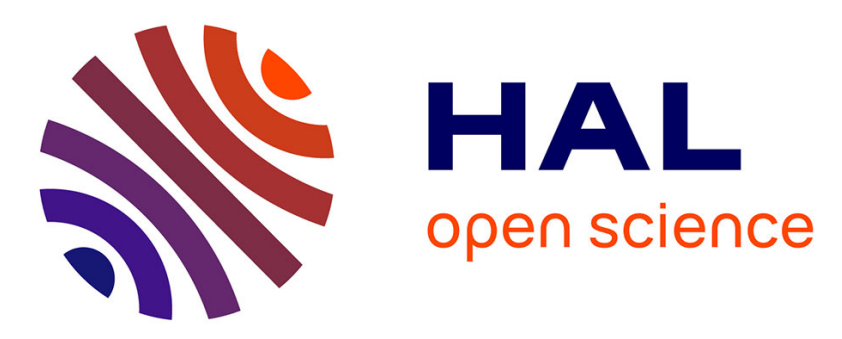

\title{
Cell mechanics of alveolar epithelial cells (AECs) and macrophages (AMs).
}

Sophie Féréol, Redouane Fodil, Gabriel Pelle, Bruno Louis, Daniel Isabey

\section{To cite this version:}

Sophie Féréol, Redouane Fodil, Gabriel Pelle, Bruno Louis, Daniel Isabey. Cell mechanics of alveolar epithelial cells (AECs) and macrophages (AMs).. Respiratory Physiology \& Neurobiology, 2008, 163 (1-3), pp.3-16. 10.1016/j.resp.2008.04.018 . inserm-00347982

\section{HAL Id: inserm-00347982 https://www.hal.inserm.fr/inserm-00347982}

Submitted on 17 Dec 2008

HAL is a multi-disciplinary open access archive for the deposit and dissemination of scientific research documents, whether they are published or not. The documents may come from teaching and research institutions in France or abroad, or from public or private research centers.
L'archive ouverte pluridisciplinaire HAL, est destinée au dépôt et à la diffusion de documents scientifiques de niveau recherche, publiés ou non, émanant des établissements d'enseignement et de recherche français ou étrangers, des laboratoires publics ou privés. 
Respiratory Physiology \& Neurobiology

Special Issue on Respiratory Biomechanics

\begin{abstract}
Manuscript:
Cell mechanics of alveolar epithelial cells (AECs) and macrophages (AMs)
\end{abstract}

Sophie Féréol ${ }^{1,2}$, Redouane Fodil ${ }^{1,2}$, Gabriel Pelle ${ }^{1,2,3}$, Bruno Louis ${ }^{1,2}$, Daniel Isabey ${ }^{1,2}$

(1) Inserm, UMR841, Biomécanique Cellulaire et Respiratoire, Créteil, F-94010, France

(2) Université Paris 12, Faculté de Médecine, UMR S 841, Créteil, F-94010, France

(3) AP-HP, Hôpital Henri Mondor, Service de Physiologie - Explorations Fonctionnelles, Créteil, F-94010 France

Correspondence address:

Daniel Isabey

Inserm UMR 841, Equipe Biomécanique Cellulaire et Respiratoire

Faculté de Médecine

8, rue du Général Sarrail

94010 CRETEIL Cedex, France

Phone: 33149813700

Fax: 33148981777

E-mail: daniel.isabey@inserm.fr 


\section{ABSTRACT}

Cell mechanics provides an integrated view of many biological phenomena which are intimately related to cell structure and function. Because breathing constitutes a sustained motion synonymous with life, pulmonary cells are normally designed to support permanent cyclic stretch without breaking, while receiving mechanical cues from their environment. The authors study the mechanical responses of alveolar cells, namely epithelial cells and macrophages, exposed to well-controlled mechanical stress in order to understand pulmonary cell response and function. They discuss the principle, advantages and limits of a cytoskeleton-specific micromanipulation technique, magnetic bead twisting cytometry, potentially applicable in vivo. They also compare the pertinence of various models (e.g., rheological; power law) used to extract cell mechanical properties and discuss cell stress/strain hardening properties and cell dynamic response in relation to the structural tensegrity model. Overall, alveolar cells provide a pertinent model to study the biological processes governing cellular response to controlled stress or strain. 


\section{Introduction}

Cells live in constant interaction with their environment, which means interdependence - and consequently mutual influence - between cells and the surrounding tissues. This interdependence is necessary for life, as the extracellular environment (ECE) contributes to cell function while cells contribute to tissue stability and mechanical properties. This means that the behavior and function of tissues and organs depend on a complex interplay of the tensile and mechanical properties of cells, while the mechanical properties of tissues and organs influence cell function in a tissue-specific manner (Engler et al., 2004; Suki et al., 2005).

The old view that considered that living tissues were made of similar reproducible elementary pieces, (i.e., cells), so that the overall macro-scale behavior, (e.g., of an organ), reflects the micro-scale behavior of the independent but identical elements, is certainly not appropriate. Most recent theories emphasize the complexity of biological systems and their nonlinear behavior in response to increased loadings or time, which has been thought to reflect cell adaptability to internal or environmental changes (Matthews et al., 2006; Mizuno et al., 2007). The global architecturally-based approach previously proposed by Buckminster Fuller (Buckminster Fuller, 1975) includes the now classical concept of "synergy" according to which the "behavior of whole systems is unpredicted by the behavior of their parts taken separately". This is precisely what happens in normal living tissue and it is easy to imagine the role of the numerous biological and mechanical interactions mediated by the many proteins and subcellular structures whose precise roles have yet to be investigated. The concept of idealized tensegrity structure was also invented by Buckminster Fuller (Buckminster Fuller, 1975) and subsequently introduced by Ingber et al. to describe the cellular system (Ingber, 1993; Ingber, 1997; Ingber, 2003a; Ingber, 2003b). 
Using such a structural model, our group has shown that the overall mechanical behavior of tensegrity structures with linear elements is indeed nonlinear, as stress or strain increased because structural elements - in self-equilibrium (i.e., tensional and compressive elements) - are spatially redistributed, thereby enhancing the contribution of geometric nonlinearities for strains greater than 10\% (Wendling et al., 1999; Wendling et al., 2000). Such a simplified cytoskeleton structure is nothing more than a composite system, e.g., tension in actin stress fibers and compression in microtubules and/or extracellular environment, in which mechanical equilibrium results from the mechanical interaction between various elements working in opposition. The frequency-dependent behavior of viscoelastic tensegrity structures depends on the spatial redistribution of its elements and the mechanical properties of the overall structure exhibit a power-law frequency dependence similar to that observed in many recent living cell experiments (Balland et al., 2006; Desprat et al., 2005; Fabry et al., 2003; Trepat et al., 2007) including those reported below in this chapter.

Recent attempts to describe, according to theoretical models and multivariate analysis, the biological response to mechanical signals at the cellular or molecular levels, e.g., substrate stiffness; contractility; ligand density; activator levels; growth factor stimulation, have revealed nonlinear response maps whether models are thermodynamic (Engler et al., 2004; Nicolas et al., 2004), kinetic (Zaman et al., 2005) or purely mechanical (Bischofs and Schwarz, 2003). These nonlinear responses are not necessarily quadratic but rather bellshaped, i.e., biological systems exhibit optimal responses in a given range of "functional" input values. It must be remembered that many pathological dysfunctions result from mechanical alterations in cell-cell interactions and between cells and surrounding tissues. 
Cell mechanics provides an integrated view of many biological phenomena which are intimately related to cell structure and function, while also reflecting - in an unknown way the interactions with the Extracellular Environment (ECE) composed of neighboring cells and/or Extracellular Matrix (ECM) (Planus et al., 1999) and the underlying connective tissue (Féréol et al., 2006). Normal cells not only apply forces on the surrounding tissues onto which they adhere and migrate, but they also respond to mechanical stimuli via reorganization of the cytoskeleton involving intracellular actin-binding proteins, molecular actomyosin motors, and adhesion proteins. The physical properties of tissues can also change during disease, thereby affecting cell-ECE interactions. A number of recent studies have suggested that the pathological orientation of cell function depends on the change in ECE properties (Engler et al., 2004; Paszek et al., 2005; Solon et al., 2007).

Because breathing constitutes a sustained motion synonymous with life, pulmonary cells are normally designed to support permanent cyclic stretch without breaking while receiving mechanical cues from their ECE (Suki et al., 2005). During mechanical ventilation, especially in diseased lungs, alveolar cells are exposed to high stretching (Hubmayr, 2005; Pugin et al., 1998). Alveolar cells could therefore provide pertinent cell models to study cell interactivity in the case of mechanically modified ECE and cell adaptation to stress or strain. The interactions of Alveolar Macrophages (AMs) with either other cell types, or organic and inorganic materials, are essential for many lung cell functions such as adhesion to alveolar epithelium, particle recognition and selective destruction. Respiratory epithelium is particularly exposed to various injuries, which can lead to lung injury syndrome. This syndrome is characterized by epithelial and endothelial damage together with alterations of the alveolar basement membrane (Ware and Matthay, 2000). When exposed to inflammatory factors such as thrombin, lung AECs tend to increase their stiffness (Trepat et al., 2005). Stretching these thrombin-treated cells resulted in profound changes in cell mechanics, but 
uniquely when cell-cell junctions were reduced or absent, suggesting that epithelial barrier dysfunction is exacerbated in injured lungs subjected to mechanical ventilation (Trepat et al., 2006). A better understanding of the mechanical response of pulmonary cells submitted to well-controlled mechanical stress and predetermined environments is therefore essential to understand pulmonary cell response and function and, presumably in a near future, cell-ECE interaction mechanisms.

We presently consider two types of pulmonary cells, i.e., alveolar epithelial cells (AECs) and alveolar macrophages (AMs) which are fundamentally different in terms of structure and function, while continuously interacting and cooperating in the same physiological environment, namely the alveoli. These physiological specificities are discussed in section two and we will then discuss the principle, advantages and limits of a cytoskeletonspecific micromanipulation technique based on transportable probes, namely micrometer-size beads that could subsequently be used in in vivo experiments to study in situ pulmonary cell mechanics. The magnetic bead twisting cytometry technique could be one of these inhaled particle techniques consistent with its clinical origin initiated several decades ago (Cohen, 1973). The data obtained ex-vivo with recent models (e.g., rheological, polymer-type) used to extract cell mechanical properties and the models used to relate experimental results to cell structure and extracellular mechanical properties will then be reviewed. This review suggests that AECs interacting with AMs provide a pertinent integrated model to study the role of cellular structure and extracellular properties on the biological-mechanical cellular response.

\section{Main biological functions of alveolar cells}

\subsection{Alveolar Epithelial Cells (AECs)}


The alveolar epithelium is composed of type I and type II AECs (Fig. 1). Type I AECs cover $93-97 \%$ of the alveolar surface and form the epithelial component of the thin air-blood barrier. They are large squamous cells that are not capable of division. The majority of their cytoplasm forms thin cytoplasmic sheets that extend over a distance of about $50 \mu \mathrm{m}$ or more from the nucleus. Like those of endothelial cells, these squamous extensions contain only very few organelles, except for numerous pinocytotic vesicles.

Type II AECs are cuboidal cells dispersed throughout the alveoli, lying between type I cells, and over the remaining $3-5 \%$ of the surface area. Type II AECs are capable of cell division. They act as the progenitor cells for the alveolar epithelium, proliferating to replenish the epithelium and form the terminally differentiated type I AECs. These cells basically secrete material, i.e., the surfactant that regulates surface tension in alveoli to prevent alveolar collapse, enhances clearance of inhaled particles; helping to prevent transudation of interstitial fluid into the alveolus. Alveolar epithelium can be seen as a continuously renewing tissue, as it comprises a population of type II AECs that are characterized by an almost unlimited potential to proliferate. Apoptosis, or programmed cell death, is an important mechanism of cell removal that was recognized a long time ago, allowing removal of excess cells in order to avoid a steady increase of the cell mass (Fine et al., 2000). Apoptotic type II AECs appear to be removed not only by macrophages but also by adjacent type II AECs (Fehrenbach et al., 2000). Type I AECs may be severely damaged under pathological conditions. Type II AECs play a key role in the cellular adaptation in response to lung injury. Viral and bacterial pulmonary infection may cause a syndrome of acute respiratory insufficiency in which the alveolar region plays a crucial role, notably via alteration of the functions of type I and II AECs.

Isolated type II AECs cultured in vitro lose their specific features within days and acquire type I epithelial cell characteristics, becoming flattened and ceasing surfactant 
production (Campbell et al., 1999; Danto et al., 1995). This process, which is highly dependent on culture conditions, is often termed transdifferentiation although it is known not to result in terminally differentiated type I AECs. Astonishingly, in vitro transdifferentiation is at least partially reversible (Danto et al., 1995), but it is not known whether the reversibility of differentiation of type II AECs into type I AECs is a potential regulatory mechanism in vivo.

Although it would be pertinent to investigate type I epithelial cell responses, a primary culture system is still not available, hence the scarce data available on type I AECs. Isolation and culture of alveolar type I AECs is difficult, partly because of their very thin cytoplasmic extensions, while intercellular junctions may be very tight and also because of the problems of isolating purified functional populations of Type I AECs from adult lung.

Continuous cell lines are an alternative to primary type II epithelial cell cultures. Finally, only two representative cell systems can be used to investigate AECs: (i) primary rattype II epithelial cell cultures at various stages of differentiation (Rannels, 1996), and (ii) human continuous cell lines including A549 (Kawkitinarong et al., 2004; Planus et al., 1999; Stroetz et al., 2001); H441 (Chess et al., 2000), and MLE-12 (Waters et al., 1999).

\subsection{Alveolar Macrophages (AMs)}

AMs constitute the predominant population of pulmonary macrophages. They are

derived from the bone marrow and are replenished in the alveoli via a steady-state process. They are large mononuclear highly phagocytic cells found on the alveolar surface. Like polymorphonuclear leukocytes or neutrophils, mononuclear phagocytes such as AMs are mobile and easily recruitable cells that deal aggressively with infection. However, they are also present even in the absence of infection or particle challenge. They constitute the first line of phagocytic defense in the lower airways and function under conditions of continuous 
exposure to pathogens or inhaled substances due to their exposed position in the alveolar lumen.

To avoid damage to adjacent type I or II cells in response to harmless antigens, they basically remain in a quiescent state, producing few inflammatory factors (e.g., cytokines), and displaying poor phagocytic activity (Holt, 1978) except when they get activated. Although large numbers of infectious particles are continuously deposited in the lungs, the alveolar surface is usually sterile (Laurenzi et al., 1961). The phagocytic and lytic potential of AMs provides most of the known bactericidal properties of the lungs. Like other phagocytes, AMs are rich in lysosomes. Lysosomes attach themselves to the phagosomal membrane surrounding the ingested pathogen. Lysosomal membranes then become continuous with the phagosomal membrane (forming a phagolysosome) and lytic enzymes kill and digest the bacteria. Particles deposited in alveoli may be removed from the alveoli by AMs that find their way into bronchioles from where they can be transported to the pharynx by the mucociliary system (Sorokin and Brain, 1975). Phagocytosis involves both types of movements which result from contractile mechanisms associated with actomyosin motors. Cellular adhesion is a key phase for phagocytosis and migration toward inflammatory sites. Like other invasive cells functioning at cross tissue boundaries, e.g., osteoclasts and dendritic cells, the adhesion system of AMs is composed of highly dynamic, actin-rich adhesion structures linked to microtubules called podosomes (Linder and Aepfelbacher, 2003). The initial contact between the phagocyte and the particle is mediated by physicochemical adhesion mechanisms. A recent study has shown that, in order to prevent damage to the alveoli, macrophages self-regulate their innate immune response (e.g., phagocytosis and secretion of proinflammatory factors such as TNF and IL6). The macrophage response to dangerous antigen presentation consists of detachment of their contacts with AECs (Takabayshi et al., 2006). This suppression of cell-cell interactions causes 
a rapid decrease in $\alpha_{v} \beta 6$ integrin expression allowing the macrophage to escape from TGF $\beta$-inhibition and lose its quiescent innate (non-activated) state.

Lung disease may arise from failure or inappropriate activation of these defense mechanisms. Failure of one of the steps leading to phagocytosis or lysosomal function leads to opportunistic infections. Some microorganisms, particularly virulent intracellular parasites (e.g., bacteria or virus), have been shown to possess characteristics that allow them to survive in normal macrophages (Armstrong and Hart, 1971). In terms of pathogenesis of lung diseases, AMs must be considered in relation to other alveolar cells and their secretions.

The terms "alveolar" or "pulmonary" macrophages refer to macrophages obtained by lung lavage, meaning that the alveolar macrophage population is not really homogeneous and may well represent one or several atypical and functionally distinct populations of macrophages in the lung (Walker, 1974). Some macrophages may have a bronchial origin instead of an alveolar origin, hence the importance of using not the first, but the second or even the third lung lavage (Féréol et al., 2006). Moreover, the number and possibly the degree of activation of cells may depend on the host's history of exposure.

\section{Mechanical properties of AECs and AMs}

\subsection{Living cell cultures and feasibility of cell probing by microbeads}

The data analyzed in this chapter were obtained from living cell cultures selected for their physiological / pathophysiological interest, i.e., A549 human cell lines and rat AMs. Cocultures of primary AMs and primary rat-type II epithelial cell were also used to provide realistic cellular substrates for AMs. The protocols used have been described in full in previous papers, e.g., A549 cell line culture was described in (Laurent et al., 2003; Planus et al., 1999) for our group and in (Kawkitinarong et al., 2004; Stroetz et al., 2001; Vlahakis et al., 1999) for other groups; AMs and primary type II AECs were described in (Féréol et al., 
2006) and (Planus et al., 1999). However, this choice of cell model presents a number of advantages and limitations, as described below.

On the one hand, A549 cell lines present the main characteristic features of type II AECs of the pulmonary epithelium: when forming a monolayer, A549 cells adopt a polygonal shape and are closely packed, exhibiting a clear and uniform distribution of lamellar bodies (Stroetz et al., 2001); they express a variety of cytokines, growth factors and receptors such as integrins that allow attachment of RGD-coated microbeads onto their apical face (Wang et al., 1993) and intercellular adhesion molecule-1 (ICAM-1) after treatment with Tumor Necrosis Factor- $\alpha$ (Planus et al., 2005); they possess functioning proinflammatory signaling pathways and synthesize lecithin and phosphatidylcholine (Vlahakis et al., 1999). Moreover, A549 cells have been shown to exhibit metabolic and transport properties consistent with type II AECs in vivo and, importantly do not functionally differentiate in culture to Type I AECs (Foster et al., 1998). A recent study showed that A549 cells still have the ability to form adherent and tight junctions when grown to confluence (Kawkitinarong et al., 2004). Therefore, despite the limitations inherent in transformed cell lines, A549 cell lines appear to be a suitable cellular model to study the mechanical response of AECs.

Primary rat-type II AECs form a polarized monolayer of type II cells after 5 days with a marked apico-baso-lateral polarity with tight junctions. This cellular polarity results in a drastic redistribution of integrin receptors to the basal part of the cell, making access of microbeads coated with RGD peptide to integrin receptors at the apical surface physically impossible (in contrast with A549 cell lines), thereby compromising RGD-coated bead twisting measurements. The typical phenotype of primary rat-type II AECs, e.g., tight cellular junction; reduced permeability of the epithelial monolayer and acquisition of the apico-basal polarity, have been systematically found and thoroughly reported in several publications over the last ten years (Féréol et al., 2006; Galiacy et al., 2003; Planus et al., 1999). 
Primary culture of AMs appears as isolated adherent cells able to recognize and partially phagocyte RGD-coated ferromagnetic beads (Chromium oxide) with a mean diameter of $4.5 \mu \mathrm{m}$ (Féréol et al., 2006). To study macrophage functions (e.g., phagocytosis, phagosome motion), J7774A.1 monocyte macrophage cell lines have been used with noncoated ferromagnetic iron-oxide particles with a mean diameter of $1.4 \mu \mathrm{m}$. Ninety per cent of these beads were found to adhere to the macrophage culture (Möller et al., 2001; Möller et al., 2000). Moreover, due to the role played by a provoked loss in cytoskeleton integrity induced by cytochalasin $\mathrm{D}$ treatment, the actin cytoskeleton can be considered to play a key role in these two macrophage studies. The main difference between the above two protocols concerns the bead coating and the differences in terms of particle incubation time: 30 minutes in (Féréol et al., 2006) versus several hours in (Möller et al., 2001; Möller et al., 2000). The main consequence is the degree of endocytosis, as particles were only partially immersed in (Féréol et al., 2006) and totally immersed in (Möller et al., 2001; Möller et al., 2000). Note that differences related to the nature of the cell culture (i.e., primary versus cell line) might also play a role in the reported differences in macrophage response.

\subsection{Magnetic Twisting Cytometry (MTC)}

\subsubsection{Principle of the MTC technique}

Magnetic Twisting Cytometry, constructed in the laboratory, allows characterization of the cytoskeletal viscoelastic properties averaged (homogenized) over a large population of living adherent cells (i.e., the culture well is about $6 \mathrm{~mm}$ in diameter) following the principle initially proposed by Wang et al. (Wang et al., 1993). Cell mechanical properties are obtained 
by probing cultured cells through coated ferromagnetic microbeads $(\varnothing: 4.5 \mu \mathrm{m})$ via which a magnetic torque (range $450-1200 \mathrm{pN} \times \mu \mathrm{m}$ ) is applied to the cell.

$\overrightarrow{\mathrm{C}}=\mu_{0} \vec{m} \wedge \vec{H}$ i.e., $C=\mu_{0} m H \sin \left(\frac{\pi}{2}-\theta_{\text {eq }}\right)$ (with $m \approx 2.310^{-13} \mathrm{Am}^{2}$ )

$m$ is the modulus of the bead magnetic moment obtained after calibration. To increase the magnetic torque, it is sufficient to increase the current in Helmholtz coils which generate the uniform perpendicular field $\vec{H}$. Note that MTC measurements cannot be performed with a sufficient level of confidence when the projected values of the remanent magnetic field are too small, e.g., for values clearly above the noise level of the measurement system, i.e., magnetometer and probes. A density of 2 beads per cell corresponds to a remanent field of 0.8 $\mathrm{nT}-1 \mathrm{nT}$, which is clearly above the $0.25 \mathrm{nT}$-noise level of the magnetometer probes. This is why applied torque values cannot be less than $400 \mathrm{pN} \times \mu \mathrm{m}$ to obtain a measurable change in remanent field. On the contrary, to avoid excessive heating in the Helmholtz coils C must be $\leq 1200 \mathrm{pN} \times \mu \mathrm{m}$, i.e., $\mathrm{I} \approx 15 \mathrm{~A}$. The resulting cytoskeleton deformation - which depends on the mechanical and biological state of the cytoskeleton - is estimated on the basis of the mean bead rotation angle deduced from the change in the projected bead magnetic moment averaged over all beads (e.g., the "translation" component is not considered in MTC in contrast with optical MTC). As previously proposed by Wang et al. (Wang et al., 1993), the bead rotation angle is continuously measured by the change in magnetic bead moment, using a theoretical formula which assumes homogeneous bead rotation:

$$
\langle\theta(\mathrm{t})\rangle=\operatorname{arc} \cos \left(\mathrm{B}(\mathrm{t}) / \mathrm{B}_{0}\right)
$$

The MTC method covers an intermediate range of cellular deformation (bead rotation angles: $\left.15^{\circ}-60^{\circ}\right)$ and, due to the large number of probes $\left(\sim 10^{5}\right.$ beads in a culture of $\sim 5 \cdot 10^{4}$ cells), provides homogenization of the cell behavior on each culture tested. This is particularly 
important assuming a possible nonlinear cellular behavior as stress or strain increases (Ohayon et al., 2004).

The applied magnetic torque used in this study is a roughly trapezoidal signal with a torque plateau lasting about $1 \mathrm{~min}$, followed by a 30 -second relaxation period, i.e., roughly a creep function. The cytoskeleton structure is assumed to reach a quasi-static mechanical equilibrium at the end of both the loading and unloading periods.

\subsubsection{In vivo motivation for MTC measurements}

Among the various well known micromanipulation methods currently available (e.g, Micropipette Aspiration, Optical Tweezers, Microplates, Atomic Force Microscopy, Magnetic tweezers, Optical Magnetic Twisting Cytometry, Magnetic Twisting Cytometry), only Magnetic Twisting Cytometry (MTC) could be adapted for future in vivo applications including in humans (Féréol et al., 2006; Wang et al., 1993). MTC was developed from magnetopneumography (MPG) which uses ferromagnetic iron-oxide particles as a tracer to investigate macrophage functions, cytoskeletal integrity and long-term clearance from the alveolar region of the human lung (Stahlhofen and Moller, 1993). These particles are nontoxic, noncarcinogenic (Stokinger, 1984), chemically stable and can be inhaled and detected as markers of pulmonary cell response notably macrophages. The weak $(\sim 0.1 \mathrm{nT})$ remanent magnetic field (or better a map of this field) is detected by a superconducting quantum interference device (SQUID). In the near future, mapping of particle deposition including in the alveolar regions and the time-course of these spatial images could be acquired by Helium-3 Magnetic Resonance Imaging (MRI) in the presence of magnetic particles. We are aware that in vivo MTC experiments would be somewhat problematic due to the large 
number of sources of heterogeneity in living tissues. However, we expect that constant improvement of signal processing and the versatility of recent MRI procedures will allow the use of ferromagnetic alveolar probes delivered at the entrance to the airways to measure the cellular response in patient lungs in situ.

\subsubsection{Constitutive torque-bead displacement relationships}

Because the bead is functionalized so that part of the bead is connected to transmembrane mechanoreceptors and subsequently to the actin cytoskeleton, the bead is partially immersed inside the cell cytoplasm with a degree of bead immersion depending on cell phenotype. Bead displacement in the cell at a given torque is easier when the bead is less deeply immersed. The half-angle generating the cone limiting the contact area is called $\alpha . \alpha$ characterizes the degree of bead immersion. To determine the $\alpha$-dependence of the measured Young modulus (E) of the cellular medium, we characterized the torque-rotation angle relationship from elasticity theory. The mechanical coupling between the bead and the cell was analyzed by (i) an analytical approach based on linear elasticity (Laurent et al., 2002b) and (ii) a numerical approach assuming nonlinear elastic behavior of the cell (Ohayon et al., 2004). The bead is in equilibrium between a magnetic torque (Eq. 1) and a reacting elastic torque $\mathrm{C}_{\mathrm{e}}$ which depends on the mechanical properties of the cell. The rigid spherical bead acts as a probe of the mechanical properties of the surrounding intracellular medium. The volume and weight of the microbeads used are so small that gravity, buoyancy and inertial effects can be neglected. At quasi-static equilibrium $\left(\theta=\theta_{\text {eq }}\right)$, the relationships between the elastic torque $C_{e}$ and the bead rotation angle $\theta_{e q}$ are given by the following analytical expressions (Laurent et al., 2002b) for three typical cases depicted in Fig. 2A-C: 
-The bead is fully immersed in an infinite medium $(\alpha=\pi$, Fig. 2 C):

$\mathrm{C}_{\mathrm{e}}=-(8 / 3) \pi \mathrm{R}^{3} \mathrm{E} \theta_{\text {eq }}$

- Half the bead is immersed in a semi-infinite medium $(\alpha=\pi / 2$, Fig. 2 B):

$\mathrm{C}_{\mathrm{e}}=-(4 / 3) \pi \mathrm{R}^{3} \mathrm{E} \theta_{\mathrm{eq}}$

-The bead contact is a small circular area (small $\alpha$, Fig. 2 A):

$$
C_{e}=-(4 / 3) \pi R^{3}\left(\sin ^{3} \alpha\right) E \theta_{\text {eq }}
$$

The stress tensor components can be calculated at any point of the bead surface by the formula given in (Laurent et al., 2002b). At a given torque, the bead rotation angle in the case of half bead immersion is twice that expected for a bead in an infinite medium and several orders of magnitude larger in the case of small bead immersion. Note that the local tension $\mathbf{T}$ $=[\sigma] \mathbf{n}$ is not homogeneous over the spherical surface, neither in modulus nor in direction $(\mathbf{n}$ represents the unit vector normal to the bead surface). In the case of rotation, the magnitude of the mean shear stress component can be estimated by the formula:

$<\sigma>\approx \mathrm{E} \theta_{\mathrm{eq}}=-\frac{\mathrm{C}_{\mathrm{e}}}{\kappa(4 / 3) \pi \mathrm{R}^{3}}$

Considering the different degrees of bead immersion, we obtain: $\kappa=2(\alpha=\pi$, Fig. 2 C), $\kappa=1$ $\left(\alpha=\pi / 2\right.$, Fig. 2 B) and $\kappa=\sin ^{3} \alpha$ (small $\alpha$, Fig. 2 A). Taking the case $\kappa=1(\alpha=\pi / 2$ or half bead immersion, Fig. 2 B) as a reference in terms of standard values of stress applied, an apparent elastic modulus $\mathrm{E}_{\text {app. }}=\frac{\mathrm{C}}{\mathrm{V}_{\text {bead }} \theta_{\text {eq }}}$ can be defined. $\mathrm{E}_{\text {app. }}$ corresponds to the elastic modulus implicitly used in many early MTC studies (Wang et al., 1993) and many subsequent MTC studies (Planus et al., 1999; Pourati et al., 1998) in which the degree of bead immersion was ignored.

$$
\kappa=E_{\text {app }} / E_{\text {cell }}
$$


The geometrical factor $\kappa$ represents the ratio of apparent to cellular elastic modulus. Values of $\kappa$ corresponding to the three typical cases above are plotted versus the degree of bead immersion $\alpha$ in Fig. 2D. To obtain a more precise estimate of the geometrical effect, we also used a numerical model whose characteristics are defined in (Ohayon et al., 2004) and (Ohayon and Tracqui, 2005) assuming a nonlinear or linear cellular material, respectively. Numerical results are plotted in the graph of the same Fig. 2D already presented in (Féréol et al., 2006). Note that the analytical and numerical solutions are in agreement below $\alpha \approx 30^{\circ}$. Thus, for small $\alpha$-values, i.e., the range of validity of the analytical solution, the proposed geometrical (and correction) factor $\kappa\left(=\sin ^{3} \alpha<<1\right)$, which is based on constitutive torquedisplacement relationships, may avoid dramatic underestimation of the measured cellular rigidity. Differences between discrete analytical and numerical solutions for $\alpha=\pi$ are simply due to geometrical differences between beads immersed immediately below the cell surface and full immersion of the bead, deeper in the cellular medium.

Accurate estimation of the bead immersion angle is critical and depends on cell phenotype. The best solution is to use spatial reconstructions of the F-actin cytoskeleton derived from the fluorescent intensity of horizontal optical sections examined by confocal microscopy (Fodil et al., 2003). The F-actin network can be classically revealed by staining with fluorescent phallotoxin. 3D reconstructions of the F-actin and bead positioning can then be performed based on a limited number of cell or beads. A representative value of the halfangle of bead immersion $\alpha$ can be obtained (after a standard 30-min bead incubation) from measurements of half the angle constructed, in a vertical section, from the bead center to the two contact points with F-actin (Laurent et al., 2002b). Values ranging from $36^{\circ}$ to $86^{\circ}$ with $\langle\alpha\rangle=67^{\circ}$ were obtained in alveolar epithelial cell lines (A549). In AMs, typical values of half-immersed angle of beads were situated in the range $100^{\circ}-130^{\circ}$ (Féréol et al., 2006). Fig. 3 provides an illustration of the method used to quantify the immersion angle in AECs and 
AMs. By comparison, the electron microscopic image of a bead attached to a Smooth Muscle Cell (SMC) (Fabry et al., 2003) reveals a much smaller $\alpha$ than in AECs and AMs although $\alpha$ can only be estimated qualitatively from this type of image.

In addition to $\alpha$, at least two other important geometrical parameters influence the torquebead displacement relationships. One is the cellular height between the bottom of the bead and the basal cellular plane (Ohayon and Tracqui, 2005; Ohayon et al., 2004). The other is the mechanical properties of the substrate (Féréol et al., 2006). The distance between the bottom of the bead and the cell substrate can be estimated from the previously described 3D reconstructions of actin structure (Fodil et al., 2003; Ohayon et al., 2004). For computational values shown in Fig. 2B, the cell height is assumed to be sufficiently large to have no effect on the $\kappa=\mathrm{E}_{\text {app }} / \mathrm{E}_{\text {cell }}$ ratio. If the cell height is reduced to just a few $\mu \mathrm{m}$, the substrate mechanical properties can be "felt" by the bead, thereby contributing, i.e., modifying, the "measured" elasticity of the cell, which then becomes an "apparent" elasticity differing from the "cellular" elasticity by a factor $\left(\mathrm{E}_{\text {app }} / \mathrm{E}_{\text {cell }}\right)$, which can be calculated using formula proposed in (Ohayon and Tracqui, 2005; Ohayon et al., 2004). . In case of small distances between bottom of the bead and substrate, elasticity properties of the substrate can also be taken into account as previously done in (Féréol et al., 2006). They show that substrate stiffness began to be "sensed" by the $4.5 \mu \mathrm{m}$-microbead below a cell height of about 7-8 $\mu \mathrm{m}$.

\subsection{Microrheological models to analyze cell mechanical properties}

The microrheological response of living cells whose cytoskeleton is twisted by ferromagnetic microbeads, transiently exposed for one minute to a constant magnetic torque and then relaxed, can be described by the following time-dependent relationship linking the 
deformation, i.e., bead rotation angle $\theta(\mathrm{t})$, to the applied stress $(\sigma)$ which involves the creep function $f$ :

$\theta(t)=\sigma(0) f(t)+\int_{x=0}^{x=t} \frac{d \sigma}{d x} f(t-x) d x$

Three types of microrheological models of cellular response were tested:

(i) The single Voigt model:

$f(\mathrm{t})=\frac{1}{\mathrm{E}}+\frac{\mathrm{t}}{\eta}$

$\mathrm{E}$ and $\eta$ are the elastic modulus and viscosity modulus, respectively, characterizing the response of a viscoelastic solid of unique relaxation time: $\tau=\eta / E$.

(ii) The double Voigt model:

$f(\mathrm{t})=\frac{1}{\mathrm{E}_{1}}+\frac{\mathrm{t}}{\eta_{1}}+\frac{1}{\mathrm{E}_{2}}+\frac{\mathrm{t}}{\eta_{2}}$

$E_{1}, \eta_{1}$ or $E_{2}, \eta_{2}$ are the elastic modulus and the viscosity modulus of the two components characterizing the viscoelastic solid response of a series of rapid and slow elements with relaxation times: $\tau_{1}=\eta_{1} / E_{1}$ and $\tau_{2}=\eta_{2} / E_{2}$ with, e.g., $\tau_{1}<\tau_{2}$.

(iii) The power law:

$f(\mathrm{t})=\mathrm{A} \mathrm{t}^{\alpha}$

From the parameters of the power law, i.e., the exponent $\alpha$ and the prefactor $\mathrm{A}$, it is also possible to calculate $\mathrm{G}_{0}$, or elasticity modulus at $1 \mathrm{~Hz}$, and thereby the corresponding elasticity modulus $\mathrm{E}=\mathrm{G}_{0} / 3$ (assumption of incompressible cellular medium) from:

$\mathrm{G}_{0}=\frac{(2 \pi)^{\alpha}}{\mathrm{A} \cdot \Gamma(1+\alpha)}$

$\Gamma(1+\alpha)\left[=\int_{0}^{+\infty} e^{-x} x^{\alpha} d x\right]$ is the Gamma Euler function. Eqs. 9-11 represent the most frequent rheological models used to fit living cell data. The single Voigt model corresponds to a 
viscoelastic solid behavior considered appropriate to describe cell mechanical responses in early MTC experiments (Wang et al., 1993) and in many biological studies. The double Voigt model is given to distinguish two major cytoskeleton structures with two significantly different time constants, e.g., the cortical and deep cytoskeleton (Laurent et al., 2003). The power law dependency takes into account the fact that the intracellular medium exhibits a power law behavior over a wide frequency range (Balland et al., 2006; Fabry et al., 2001a). This means that there is a broad and dense dissipation time in the cell and that the mechanisms responsible from the storage of elastic energy and its dissipation are strongly correlated. Such experiments have been performed by applying an oscillatory torque to a ferromagnetic bead either at constant frequency, e.g., $5 \mathrm{~Hz}$ (Maksym et al., 2000), or by varying frequencies in different ranges, e.g., $10^{-1}-10^{2} \mathrm{~Hz}$ in (Trepat et al., 2004); $10^{-2}-10^{2} \mathrm{~Hz}$ in (Fabry et al., 2003) and recently, $10^{-3}-10^{3} \mathrm{~Hz}$ (Stamenovic et al., 2007). It has recently been shown (Desprat et al., 2005; Lenormand et al., 2004) that the creep function, i.e., transient application of a constant loading followed by relaxation, may be described by a power law of elapsed time such as that depicted by Eq. 1. There are numerous examples in the literature of complex viscoelastic systems showing power law rheological behaviors, e.g., colloidal systems close to sol/gel transition (Ponton et al., 2002), and "soft glassy materials" including foams, pastes, emulsions (Weeks et al., 2000). The generally accepted idea is that systems with a high degree of structural complexity, which is the case of cells, require a large possibly even infinite - number of characteristic relaxation times because their mechanical dissipation is a multiscale dynamic process (Fabry et al., 2003). It has been postulated that cells behave like out-of-equilibrium and disordered systems in which multiscale structural rearrangements dominate through dynamic cross-linking, actin polymerization, and molecular motor activity (Lenormand et al., 2007). To relate this type of quite formal representation of cell behavior to cytoskeleton dynamics occurring at a multitude of length scales (i.e., from 
individual actin filaments to cell size actin bundles or stress fibers) and thus characteristic times $\tau_{t}$, Balland et al. (Balland et al., 2006) considered that the cell structure is composed of an infinite series of Voigt elements with self-similar structures. These structures are distributed according to the ideal power law: $\tau_{i}=\tau_{m} i^{\left(\frac{-1}{1-\alpha}\right)}$ (where $\tau_{m}$ represents the largest relaxation time in the cell), and the authors demonstrated that the resulting creep function follows a power law of time, whether or not some natural dispersion in the time relaxation distribution is included. Although a description in terms of elementary Voigt units may appear oversimplified to take into account active molecular mechanisms related to molecular mechanisms or filament remodeling, the various relaxation times associated with each viscoelastic unit can be considered to represent the storage and dissipation of elastic energy in actin filaments, bundles, and stress fibers. Dissipation itself may include several processes, such as cytoskeleton remodeling, molecular motor activity, and passive viscosity (Balland et al., 2006). Note that it is not clear whether such a precise description at the molecular level, i.e., with an infinite number of relaxation times including very short relaxation times, is necessary to describe macroscopic mechanical behavior, which is why we propose comparative analysis for the present approach, based on Eqs 9 to 11, of experimental data with both simplified highly integrated models (Eqs 9 and 10) and multiscale highly complex models (Eq. 11). Another important specificity of the proposed approach is to consider the stress/strain dependence of microrheological results, namely the nonlinear cellular mechanical behavior. The stress-strain dependent mechanical feature of cells is highly informative and can reveal the passive and/or active structural origin of the mechanical response from largescale geometrical effects (Ohayon et al., 2004; Wendling et al., 1999) to the molecular scale at which molecular motors act (Cai et al., 1998; Mizuno et al., 2007).

\subsection{Mechanical properties of living AECs versus AMs}


MTC data were analyzed comparatively in alveolar epithelial A549 cell lines (AECs) and primary culture of AMs over a complete measurement cycle: e.g., cell loading (magnetic torque) applied for one minute followed by unloading or cell relaxation for less than one minute. Under these culture conditions, the cells were mostly resting and stable. AECs formed a stable confluent monolayer (24 hours after seeding) on top of which ferromagnetic beads were attached for $30 \mathrm{~min}$. AMs are isolated, adherent, mostly resting cells, plated in the absence of chemoattractant for 3 hours which is the optimal time for macrophage stability. Cell mechanical properties obtained from best curve fitting of experimental data are plotted for AECs and AMs in Fig. 4 for the single Voigt model (Eq. 9), Fig. 5 for the double Voigt model (Eq. 10), and Fig. 6 for the power law model (Eq. 11). In this analysis, the exact magnitude of the magnetic torque (Eq. 1), which depends on bead rotation angle calculated by Eq. 2, was taken into account. The magnetic torque applied to the beads was in the range 400$1200 \mathrm{pN} \times \mu \mathrm{m}$, the various torque values (or stress values given by Eq. 6) were obtained at four different values of $\mathrm{H}$ (Eq. 1) and at various bead rotation angles (angular deformation values deduced from Eq. 2). The half-angle of bead immersion specific to each cell type was also taken into account on the basis of angle estimates described above (see Fig. 2B).

The single Voigt model provided satisfactory curve fitting (i.e., $\left\langle\mathrm{r}^{2}\right\rangle=0.935$ ) of the experimental curves of bead rotation versus time). Fig. 4 A-C shows that resting AMs are basically softer than AECs, while AMs and AECs exhibit a markedly different behavior in response to increasing magnetic torques. Indeed, AECs exhibit a significant stress-dependent increase in cell stiffness (in Fig. 4A) consistently with the highly nonlinear torque-rotation relationships (latter shown in Fig. 8), while AMs elasticity modulus remained almost independent of stress. The cellular viscosity of both AECs and AMs was, for any stress level, at least one order of magnitude smaller for AMs than for AECs and the torque-dependency 
was negligible (Fig. 4B). Relaxation times (in Fig. 4C) were only slightly different between AECs and AMs, and exhibited only a slight decay in $\tau$ with increasing stress, i.e., $20-10 \mathrm{~s}$ in AECs versus 2-7s in AMs.

The double Voigt model provided better curve fitting of experimental data than the single Voigt model (i.e., $\left\langle\mathrm{r}^{2}\right\rangle=0.966$ ). The two viscoelastic components corresponded to very different relaxation times, i.e., a few seconds for the rapid component for both cell types and a few hundred seconds for the slow component for both cell types (Figs. 5E and 5F). In this model (Eq. 10), the angular displacement was partitioned into two complementary angular displacements corresponding to the fast and slow components. The elasticity (Figs. 5A and 5B) and viscosity (Figs. 5C and 5D) modulus of the two components were significantly different between AECs and AMs. Noteworthy, a marked difference in viscous modulus was observed between the fast and slow components for both AECs and AMs (Figs. 5C and 5D). The marked differences in mechanical properties between the fast and slow components are consistent with marked differences in CSK substructures. We have previously provided biological and theoretical arguments based on tensegrity structures suggesting that the fast component might represent the cortical submembranous cytoskeleton, while the slow component might represent the deep cytoskeleton (Cañadas et al., 2002; Laurent et al., 2002a; Laurent et al., 2003). Longer relaxation times in the slow component suggest characteristic elements of longer size in the deep cytoskeleton compared to the cortical cytoskeleton constituted by interconnected filaments of shorter length.

The power law model provided curve fitting that was almost as good as that of the double Voigt model (i.e., $\left\langle\mathrm{r}^{2}\right\rangle=0.951$ ) and better than that of the single Voigt model. Values of the exponent $\alpha$ (see Fig. 6A) were situated in the range of many other living cell studies, namely $\alpha=0.15-0.35$ (Alcaraz et al., 2003; Balland et al., 2006; Balland et al., 2005; Fabry et al., 2003; Maksym et al., 2000; Puig-de-Morales et al., 2004; Trepat et al., 2004). This means 
that the MTC method initially defined by Wang et al. (Wang et al., 1993) and then largely used in lung cells by our group (Doornaert et al., 2003; Féréol et al., 2006; Laurent et al., 2002b; Ohayon et al., 2004; Planus et al., 1999) can provide assessment of the dynamic cell response consistent with other micromanipulation methods. It should be underlined here that $f$ the MTC method provides averaged (homogenized) values of mechanical properties over an entire cell population moreover for varying and significant stress levels. Results show that the stress-dependence of the exponent $\alpha$ remained small (Fig. 6A). By contrast, the prefactor $\mathrm{G}_{0}$ which represents the values of elasticity modulus at a given reference frequency (i.e., $1 \mathrm{~Hz}$, see Eq. 12), exhibited a stress-dependent increase in AECs but not in AMs (Fig. 6 B). On the whole, the differences between AECs and AMs were particularly marked for prefactor $\mathrm{G}_{0}$. For reasons not clearly understood yet, values of $\mathrm{G}_{0} / 3$ for both AECs (and also AMs) were close to the values of elasticity modulus of the fast component obtained with the double Voigt model (Fig. 5A). This analysis of MTC data confirms the value of the power law model to describe the mechanical responses of living cells and to a certain extent, the stress dependence of characteristic cell mechanical parameters. Consistently with literature studies, exponent $\alpha$ remains situated in a narrow range (e.g., 0.15-0.25) most likely reflecting some common structural organization of the cytoskeleton network. Moreover, present data show high sensitivity of prefactor $\mathrm{G}_{0}$ as previously reported (Balland et al., 2006). Note that the large differences in $\mathrm{G}_{0}$ values which ranged from $10 \mathrm{~Pa}$ in resting $\mathrm{AMs}$ to almost $10^{3} \mathrm{~Pa}$ in the stiffest AECs deserve further studies.

Overall, the present analysis of MTC results by the three proposed models raises new questions concerning the appropriateness of microrheological models to represent living cells. One question concerns the need to test cells at high frequencies in order to obtain a precise description of the elastic and dissipation processes at the molecular level. Another related question is why a Voigt model with only a few elementary components is able to provide 
equally good curve fitting. To the extent that the slope of the power law (see Eq. 11) is unchanged at least over a given frequency range which has been recently questioned (Stamenovic et al., 2007), it has been pointed out that the cell frequency dependency and stress relaxation function (such as Eq. 8) over this range can simply be predicted from a single frequency of oscillatory measurement (Fabry et al., 2001a; Trepat et al., 2005). A third question concerns the need for a better understanding of the biological and mechanical basis of the stress or strain relationships of the cellular response. The stress/strain dependence most likely reflects, like frequency phenomena, some of the major cellular and molecular processes and therefore deserves further attention.

\subsection{Comparison between MTC and other bead twisting techniques}

\subsubsection{Bead rotation in MTC versus translation in OMTC}

The micromanipulation technique most closely resembling MTC is OMTC (Optical Magnetic Twisting Cytometry) initially proposed by Fabry et al. (Fabry et al., 2003). OMTC is derived from MTC. OMTC uses RGD-coated ferromagnetic beads moved in a spatially uniform time-oscillating magnetic field (at frequency f) which transmits an oscillatory

magnetic torque $\tilde{\mathrm{C}}$ to the cell cytoskeleton. The front bead displacement $\tilde{\mathrm{d}}$ is measured by analyzing real-time optical microscope images. A measurement of cell mechanical properties is obtained from the real and imaginary parts of the complex elasticity modulus $\tilde{g}$ deduced from Eq 13:

$\tilde{\mathrm{C}}(\mathrm{f})=\tilde{\mathrm{g}}(\mathrm{f}) \cdot \tilde{\mathrm{d}}(\mathrm{f})$ with $\tilde{\mathrm{g}}=\tilde{\mathrm{g}}^{\prime}+i \tilde{\mathrm{g}}^{\prime \prime} \quad$ (in $\left.\mathrm{Pa} / \mathrm{nm}\right)$ and $i=\sqrt{-1}$

$\tilde{\mathrm{G}}(\mathrm{f})=\beta \tilde{\mathrm{g}}(\mathrm{f})$ (in Pa), $\beta=6.8 \mu \mathrm{m}\left(\mathrm{h}=5 \mu \mathrm{m} ; \alpha=37^{\circ}, \tilde{\mathrm{d}} \leq 500 \mathrm{~nm}\right)$ 
$\tilde{\mathrm{G}}(\mathrm{f})=\tilde{\mathrm{G}}^{\prime}(\mathrm{f})+i \tilde{\mathrm{G}}^{\prime \prime}(\mathrm{f}), \quad \tilde{\mathrm{G}}^{\prime \prime}(\mathrm{f}) / \tilde{\mathrm{G}}^{\prime}(\mathrm{f})=\tilde{h}(\mathrm{f}), \quad \tilde{h}$ : hysteresivity

The geometrical factor $(\beta)$ allows the apparent complex modulus $\tilde{g}$ to be related to the cellular complex modulus $\tilde{\mathrm{G}}$ (Eq. 14). $\tilde{G}^{\prime}(\mathrm{f})$ (real part of $\tilde{\mathrm{G}}(\mathrm{f})$ ) and $\tilde{G}^{\prime \prime}(\mathrm{f})$ (imaginary part of $\tilde{\mathrm{G}}(\mathrm{f})$ ) are the elasticity modulus (related to the stored energy) and the viscosity modulus (related to the dissipative loss of energy), respectively. Parameter $\tilde{h}(\mathrm{f})$ is the loss tangent (tangent of the phase angle between stress and strain) also called hysteresivity (Fredberg and Stamenovic, 1989). Factor $\beta$ which plays a similar role to $\kappa$ (Eq. 7), is taken to be constant and deduced from simulations based on linear elasticity assumption (Mijailovich et al., 2002) for the geometrical dimensions given in Eq. 14 (h: cell height, $\alpha$ : half-angle of bead immersion, small bead displacement). Due the fundamental role of $\alpha$ in the stress-strain relationship (see Fig. 2), precise determination of $\alpha$ is essential, especially in the case of slight bead immersion such as for smooth muscle cells (SMC). For instance, if instead of $\alpha=37^{\circ}, \alpha$ $=15^{\circ}$, the elasticity modulus would be underestimated by $\left(\sin ^{3} 37^{\circ} / \sin ^{3} 15^{\circ}\right)$, i.e., a factor of 12.

Pure torque application on a partially immersed bead - which characterizes both the MTC and OMTC methods - results in a complex motion composed of a combination of translation and rotation. The ratio of translation to rotation depends on the parameter $\alpha$. The ratio of translation to rotation (see Fig. 7) - calculated with numerical data and the assumption of linear elasticity (Ohayon and Tracqui, 2005) - decreases from 1 at low $\alpha\left(<20^{\circ}\right)$ to zero at high $\alpha\left(\sim 180^{\circ}\right)$. Below $\alpha=20^{\circ}$, all of the torque is transformed into translation. This means that the OMTC method, which uniquely measures bead translation, is particularly adapted to the mechanical assessment of low phagocytosing cells such as SMC, on which beads are only slightly immersed. Mechanical assessment of cells by fully immersed beads cannot be performed by OMTC, as in this case, torque application results in pure bead rotation. By 
contrast, the MTC method is particularly adapted to measure high phagocytosing cells such as AMs since bead rotation is measured. Since the ratio of bead translation to bead rotation is equal to or less than 1 , the contribution of bead rotation is always greater than or equal to bead translation, and bead rotation measured by MTC is therefore significant for any value of $\alpha$. This is most likely true because a torque is applied.

\subsubsection{Large versus small cellular deformation}

Magnetic torques (Eq. 1) depend on (i) perpendicular magnetic field, (ii) magnetic moments of beads used in each technique, and (iii) the sine of the complementary bead rotation angle (i.e., the cosine of the bead rotation angle). Typical maximum values of perpendicular magnetic field are: (i) 63 Gauss, i.e., $6.3 \mathrm{mT}$, in MTC studies of our group (Laurent et al., 2003; Laurent et al., 2002b; Ohayon et al., 2004, Féréol, 2006 \#16) and the present data and (ii) 70 Gauss, i.e., $7 \mathrm{mT}$ in OMTC studies by (Fabry et al., 2003). Oscillatory MTC, used by Maksym et al. (Maksym et al., 2000), must be performed at much smaller perpendicular magnetic fields, i.e., 20 Gauss, i.e., $2 \mathrm{mT}$. The torque per unit bead volume per gauss, $c$, also called bead constant, characterizes the type of bead used (bead geometry and ferromagnetic material content). In most studies, $c$ is measured from the friction of a large population of beads flowing in a viscous medium (Wang and Ingber, 1995). For spherical polystyrene beads coated with chromium oxide $(\varnothing=4.5 \mu \mathrm{m}), c$ is about $0.05 \mathrm{~Pa} / \mathrm{Gauss}$ (Wang and Ingber, 1995). In other studies (Laurent et al., 2003; Laurent et al., 2002b; Ohayon et al., 2004, Féréol, $2006 \# 16$ ) and the present data, bead magnetic moment $m$ was first obtained after measurement of bead magnetization in a bead sample using a Föner method $(m \approx 2.3$ $10^{-13} \mathrm{Am}^{2}$ (Laurent et al., 2002b)). $c$ can then be estimated by:

$\mathrm{c}=\frac{\mu_{0} \times m}{\kappa \times \mathrm{V}} \approx \frac{4 \pi 10^{-7} \times 2.310^{-13}}{6 \times 4810^{-18}} \mathrm{~Pa} / \mathrm{A} / \mathrm{m} \approx 0.001 \mathrm{~Pa} / \mathrm{A} / \mathrm{m}$, i.e., $\mathrm{c} \approx 0.08 \mathrm{~Pa} / \mathrm{G}$ 
For fully ferromagnetic $\mathrm{Fe}_{3} \mathrm{O}_{4}$ beads $(\varnothing=4.5 \mu \mathrm{m}), c$ reaches $1.86 \mathrm{~Pa} / \mathrm{Gauss}$, as reported in (Fabry et al., 2003). For a given type of material, differences in $c$ values could be attributed to the variability between bead samples and to differences in the calibration method used. A certain amount of heterogeneity cannot be ignored between beads but, at present, there is no way to separately calibrate the magnetic moment of each bead.

After geometric corrections given by Eq. 6, the values of magnetic torques in MTC studies (Laurent et al., 2003; Laurent et al., 2002b; Ohayon et al., 2004, Féréol, 2006 \#16) including the present data in AECs and AMs range between 400-1200 $\mathrm{pN} \times \mu \mathrm{m}$ at bead equilibrium. In oscillatory MTC (Maksym et al., 2000), magnetic torques are not more than $275 \mathrm{pN} \times \mu \mathrm{m}$. Magnetic torque values were not directly provided in (Fabry et al., 2003) but a rough estimate (bead volume $\sim 48 \mu \mathrm{m}^{3}$ ) indicates that the lowest magnetic torque tested might be as low as $86 \mathrm{pN} \times \mu \mathrm{m}$. The results for total bead displacement induced by magnetic torque (i.e., either deduced from bead rotation by $\mathrm{r} \cdot \theta_{\mathrm{rad}}$ in MTC experiments or measured directly in OMTC) are summarized in Fig. 8. The present data obtained in AECs and AMs show a range of curvilinear bead displacement between $500 \mathrm{~nm}$ and a maximum of $2500 \mathrm{~nm}$, as in recent MTC studies (Laurent et al., 2003; Laurent et al., 2002b) or older MTC studies (Wang and Ingber, 1995). This corresponds to bead rotation angles in the range $15^{\circ}-60^{\circ}$, i.e., relatively large cellular deformations which depend on the torque applied and obviously on cell stiffness and cell phenotype. For comparison, during OMTC measurements in Human Airway Smooth Muscle (HASM) cells, the median displacement amplitude was $57 \mathrm{~nm}$ in (Fabry et al., 2001b) and a maximum of $259 \mathrm{~nm}$ in (Fabry et al., 2003). The graph in Fig. 8 takes into account the fact that OMTC data are obtained for bead displacements less than $500 \mathrm{~nm}$ (Fabry et al., 2003). This is due to processing of OMTC data, in amplitudes of bead displacement greater than $500 \mathrm{~nm}$ are excluded from the analysis. Note that this type of bead-by-bead processing does not exist in MTC. However, beads displaced by more than $500 \mathrm{~nm}$ might reveal a 
possible nonlinear behavior, depending on cell phenotype, as, for displacement amplitudes greater than $500 \mathrm{~nm}$, harmonics might be observed on oscillatory bead displacement indicating nonlinearity. The graph presented in Fig 9 shows that the present MTC data obtained in AECs and AMs are situated in a large range of cellular deformation, i.e., greater than $500 \mathrm{~nm}$. The nonlinear behavior of AECs and the linear behavior in AMs depend on the actin-myosin apparatus, which probably differs between AECs and AMs since AECs are found to be more tensed than AMs while stress fibers are present in AECs and absent in AMs (Féréol et al., 2006). MTC and OMTC data consistently show that the reported linear behavior of cells is systematically verified in the $500 \mathrm{~nm}$-range of bead displacement, while cellular nonlinearity may be observed at higher values (Ohayon et al., 2004). The practical consequence is that the OMTC method attributes greater weight to small cellular displacements, while the MTC method tends to attribute greater weight to large cellular displacements, suggesting that the two methods do not provide contradictory but complementary data. The MTC method can therefore be considered to specifically reveal nonlinear cellular features related to structural, passive and/or active phenomena observed beyond a sufficient level of cellular deformation.

Interestingly, the bead displacement reported with Optical Tweezers (OT), which generate a unidirectional force (Laurent et al., 2002b), remains less than $500 \mathrm{~nm}$, i.e., in the linear range. Similarly, the oscillatory MTC method proposed by Maksym et al. (Maksym et al., 2000) uses $5^{\circ}$-amplitude bead oscillations, i.e., bead displacements typically remain in the linear range. It should also be emphasized that the use of very small magnetic torques, i.e., less than $400 \mathrm{pN} \times \mu \mathrm{m}$, as in the study by Maksym et al., (i.e., maximum $275 \mathrm{pN} \times \mu \mathrm{m}$ ), enhances the effect of poorly attached beads on the overall projected magnetic moment leading to marked underestimation of the cellular elasticity modulus (Fabry et al., 1999). Fig. 
8 shows that cellular displacements by more than a few microns could generate cell breakage and damage, a situation which corresponds to Ventilation Induced Lung Injury, and alters cell response (Pugin et al., 1998; Trepat et al., 2006; Vlahakis and Hubmayr, 2000).

\section{Structural rearrangement, frequency dependence and stress responses}

The frequency response and the external stress/strain-induced cellular stiffening response both reflect mechanisms that are not fully understood and consequently deserve further investigation. The present approach combines (i) MTC experiments at large cellular deformation and (ii) analysis of living cell data using three different models which describe elastic and dissipation processes at different scales of the cytoskeleton, i.e., from the macroscopic cellular level (single relaxation time) to the microscopic level (power law model with infinite number of relaxation times), including the two-component model at subcellular levels (two relaxation times).

The frequency-dependence of the mechanical response of living cells can only be demonstrated by the power law model with an infinite number of relaxation times, showing the frequency dependence of elasticity and loss modulus, which also depend on the distribution of relaxation times $\tau_{i}$. The link between relaxation times and cytoskeleton structure is based on the microscopic observation of self-similarities between cytoskeleton substructures at different scales, i.e., from large stress fiber structures at the cell scale to the structure of individual filaments at the nanometer scale. This implies that the elementary units are distributed according to a power law: the number of units with a given size $l$ is considered to be proportional to $l^{-\xi}$, where $\xi>0$ represents the fractal dimension of the network (Balland et al., 2006). The dependence of the response time $\tau_{i}$ with the size $l_{i}$ of elementary units can be depicted by a simple power law: $\tau_{i} \propto l_{i}^{\beta}$ where the exponent $\beta$ characterizes the dependence 
of the response time $\tau$ with the scale $l$. Consequently, the distribution of times $\tau_{i}$ in the cell is also described by a power law. This multi-scale coupling between elasticity and dissipation processes is a main characteristic of structural damping. Further studies must investigate the dissipative elements in terms of elementary biological mechanisms, such as molecular motor activity and crosslinker dynamics, which all play a crucial role in cytoskeleton remodeling.

The stress/strain stiffening response of living AECs has been previously related to passive quasi-static mechanical behavior of prestressed tensegrity structures at large strains. The single-relaxation time model and the two-relaxation time model both reveal a stressdependent behavior of cellular elasticity that can be related to the spatial rearrangement of structural elements at the whole cellular scale (Wendling et al., 1999) or at the subcellular scales of the cortical and deep cytoskeleton structures (Laurent et al., 2002a). To understand the role of spatial rearrangement of structural elements on cell response during imposed cyclic stresses, we numerically simulated the response to transient loading (Cañadas et al., 2002) and the frequency-dependent behavior (Cañadas et al., 2006) of a viscoelastic tensegrity structure composed of 24 elastic cables and 6 rigid bars, the same structure as the one used by Wendling et al. in static conditions (Wendling et al., 1999). For the frequency-dependent study, the viscoelastic tensegrity structure (VTS) computational model was based on the NonSmooth Contact Dynamics (NSCD) method in which the constitutive elements of the tensegrity structure are considered to be a set of material points that mutually interact (Cañadas et al., 2006). Low amplitude oscillatory loading conditions were applied and the frequency response of the overall VTS structure was studied in terms of frequencydependence of mechanical properties. The VTS results are presented in Fig 11. The elasticity and viscosity modulus, $E^{*}$ and $\eta^{*}$, were normalized by the homogeneous (i.e., constant) properties of constitutive elements in order to capture the essential feature of spatial rearrangement. The results reveal a specific frequency-dependent contribution of elastic and 
viscous effects, which are responsible for significant changes in the tensegrity model dynamic properties (see Fig. 10). The mechanism behind the frequency-dependence of the mechanical properties of the prestressed tensegrity structure is related to the non-equal contribution of spatial rearrangement of structural elements which decreases with increasing frequency, as the dominant effects are transferred from mainly elastic to mainly viscous. More precisely, the elasticity modulus increases with frequency while the viscosity modulus decreases. It is noteworthy that this time-course corresponds to a specific power-law dependency shown in Table 1. It is also noteworthy that, in the transitional zone of frequency in which elastic effects and viscous effects are both not negligible, the structural viscoelastic model behavior follows a power law dependency similar to that observed in oscillatory experiments in living cells (Alcaraz et al., 2003; Balland et al., 2005; Fabry et al., 2003; Maksym et al., 2000; Puigde-Morales et al., 2004). Such a surprisingly good agreement suggests that spatial rearrangement of structural elements might play a role in the frequency-dependent behavior of living cells.

Cellular stiffening (increased shear stiffness) actually depends on the level of the endogenous contractile prestress, which is nothing more than the prestress generated by myosin II-actin interactions. Early evidence for prestress-dependent cellular stiffening in living cells was demonstrated by (Cai et al., 1998; Hubmayr et al., 1996; Pourati et al., 1998). Recent studies by Wang et al. have provided definitive evidence of the link between cell stiffness and prestress (measured independently of each other) (Wang et al., 2001; Wang et al., 2002). Interestingly, tension in the actin polymers and not the cross-links would be the key to myosin contractile tension-induced stiffening of actin polymers (Mizuno et al., 2007), hence the need to investigate prestress-dependent stiffening at the molecular level. A notable finding was the lack of stress stiffening response in AMs that also lack stress fibers, which raises new important questions about the molecular and cellular mechanisms governing the 
response in slow tensed cells (Féréol et al., 2006). We can assume that many other vital cellular functions could also be dependent on the level of contractile prestress in living cells: cell spreading, proliferation and apoptosis (Chen et al., 1997), stress propagation and mechanical signaling (Wang and Suo, 2005; Wang et al., 2002).

\section{Acknowledgments}

The authors would like to thank Patrick Cañadas, Sylvie Hénon, François Gallet, Valérie M Laurent, Jacques Ohayon and Emmanuelle Planus for their helpful contributions. 
References

Alcaraz, J., Buscemi, L., Grabulosa, M., Trepat, X., Fabry, B., Farre, R., Navajas, D., 2003. Microrheology of human lung epithelial cells measured by atomic force microscopy. Biophys J 84, 2071-2079.

Armstrong, J.A., Hart, P.D., 1971. Response of cultured macrophages to Mycobacterium tuberculosis, with observations on fusion of lysosomes with phagosomes. J Exp Med 134, 713-740.

Balland, M., Desprat, N., Icard, D., Fereol, S., Asnacios, A., Browaeys, J., Henon, S., Gallet, F., 2006. Power laws in microrheology experiments on living cells: Comparative analysis and modeling. Phys Rev E Stat Nonlin Soft Matter Phys 74, 021911.

Balland, M., Richert, A., Gallet, F., 2005. The dissipative contribution of myosin II in the cytoskeleton dynamics of myoblasts. Eur Biophys J 34, 255-261.

Bischofs, I.B., Schwarz, U.S., 2003. Cell organization in soft media due to active mechanosensing. Proc Natl Acad Sci U S A 100, 9274-9279.

Buckminster Fuller, R. (1975) Synergetics. Macmillan Publishing Company, New York.

Cai, S., Pestic-Dragovich, L., O'Donnell, M.E., Wang, N., Ingber, D., Elson, E., De Lanerolle, P., 1998. Regulation of cytoskeletal mechanics and cell growth by myosin light chain phosphorylation. Am J Physiol 275, C1349-1356.

Campbell, L., Hollins, A.J., Al-Eid, A., Newman, G.R., von Ruhland, C., Gumbleton, M., 1999. Caveolin-1 expression and caveolae biogenesis during cell transdifferentiation in lung alveolar epithelial primary cultures. Biochem Biophys Res Commun 262, 744751.

Cañadas, P., Laurent, V.M., Oddou, C., Isabey, D., Wendling, S., 2002. A Cellular Tensegrity Model to Analyse the Structural Viscoelasticity of the Cytoskeleton. J Theor Biol 218, 155-173.

Cañadas, P., Wendling-Mansuy, S., Isabey, D., 2006. Frequency response of a viscoelastic tensegrity model: Structural rearrangement contribution to cell dynamics. J Biomech Eng 128, 487-495.

Chen, C.S., Mrksich, M., Huang, S., Whitesides, G.M., Ingber, D.E., 1997. Geometric control of cell life and death. Science 276, 1425-1428.

Chess, P.R., Toia, L., Finkelstein, J.N., 2000. Mechanical strain-induced proliferation and signaling in pulmonary epithelial H441 cells. Am J Physiol Lung Cell Mol Physiol 279, L43-51.

Cohen, D., 1973. Ferromagnetic contamination in the lungs and other organs of the human body. Science $180,745-748$.

Danto, S.I., Shannon, J.M., Borok, Z., Zabski, S.M., Crandall, E.D., 1995. Reversible transdifferentiation of alveolar epithelial cells. Am J Respir Cell Mol Biol 12, 497502.

Desprat, N., Richert, A., Simeon, J., Asnacios, A., 2005. Creep function of a single living cell. Biophys J 88, 2224-2233.

Doornaert, B., Leblond, V., Planus, E., Galiacy, S., Laurent, V.M., Gras, G., Isabey, D., Lafuma, C., 2003. Time course of actin cytoskeleton stiffness and matrix adhesion molecules in human bronchial epithelial cell cultures. Exp Cell Res 287, 199-208.

Engler, A.J., Griffin, M.A., Sen, S., Bonnemann, C.G., Sweeney, H.L., Discher, D.E., 2004. Myotubes differentiate optimally on substrates with tissue-like stiffness: pathological implications for soft or stiff microenvironments. J Cell Biol 166, 877-887. 
Fabry, B., Maksym, G., Hubmayr, R., Butler, J., Fredberg, J., 1999. Implications of heterogeneous bead behavior on cell mechanical properties measured with magnetic twisting cytometry. Journal of Magnetism and Magnetic Materials 194, 120-125.

Fabry, B., Maksym, G.N., Butler, J.P., Glogauer, M., Navajas, D., Fredberg, J.J., 2001 a. Scaling the microrheology of living cells. Phys Rev Lett 87, 148102.

Fabry, B., Maksym, G.N., Butler, J.P., Glogauer, M., Navajas, D., Taback, N.A., Millet, E.J., Fredberg, J.J., 2003. Time scale and other invariants of integrative mechanical behavior in living cells. Phys Rev E Stat Nonlin Soft Matter Phys 68, 041914.

Fabry, B., Maksym, G.N., Shore, S.A., Moore, P.E., Panettieri, R.A., Jr., Butler, J.P., Fredberg, J.J., 2001b. Selected contribution: time course and heterogeneity of contractile responses in cultured human airway smooth muscle cells. J Appl Physiol 91, 986-994.

Fehrenbach, H., Kasper, M., Koslowski, R., Pan, T., Schuh, D., Muller, M., Mason, R.J., 2000. Alveolar epithelial type II cell apoptosis in vivo during resolution of keratinocyte growth factor-induced hyperplasia in the rat. Histochem Cell Biol 114, 49-61.

Féréol, S., Fodil, R., Labat, B., Galiacy, S., Laurent, V.M., Louis, B., Isabey, D., Planus, E., 2006. Sensitivity of alveolar macrophages to substrate mechanical and adhesive properties. Cell Motil Cytoskeleton 63, 321-340.

Fine, A., Janssen-Heininger, Y., Soultanakis, R.P., Swisher, S.G., Uhal, B.D., 2000. Apoptosis in lung pathophysiology. Am J Physiol Lung Cell Mol Physiol 279, L423427.

Fodil, R., Laurent, V.M., Planus, E., Isabey, D., 2003. Characterization of cytoskeleton mechanical properties and 3D-actin structure in twisted living adherent cells. Biorheology 40, 241-245.

Foster, K.A., Oster, C.G., Mayer, M.M., Avery, M.L., Audus, K.L., 1998. Characterization of the A549 cell line as a type II pulmonary epithelial cell model for drug metabolism. Exp Cell Res 243, 359-366.

Fredberg, J.J., Stamenovic, D., 1989. On the imperfect elasticity of lung tissue. J Appl Physiol 67, 2408-2419.

Galiacy, S., Planus, E., Lepetit, H., Fereol, S., Laurent, V., Ware, L., Isabey, D., Matthay, M., Harf, A., d'Ortho, M.P., 2003. Keratinocyte growth factor promotes cell motility during alveolar epithelial repair in vitro. Exp Cell Res 283, 215-229.

Holt, P.G., 1978. Inhibitory activity of unstimulated alveolar macrophages on T-lymphocyte blastogenic response. Am Rev Respir Dis 118, 791-793.

Hubmayr, R.D., 2005. Ventilator-induced lung injury without biotrauma? J Appl Physiol 99, 384-385.

Hubmayr, R.D., Shore, S.A., Fredberg, J.J., Planus, E., Panettieri, R.A., Jr., Moller, W., Heyder, J., Wang, N., 1996. Pharmacological activation changes stiffness of cultured human airway smooth muscle cells. Am J Physiol 271, C1660-1668.

Ingber, D.E., 1993. Cellular tensegrity: defining new rules of biological design that govern the cytoskeleton. Journal Of Cell Science 104 ( Pt 3), 613-627.

Ingber, D.E., 1997. Tensegrity: the architectural basis of cellular mechanotransduction. Annual Review Of Physiology 59, 575-599.

Ingber, D.E., 2003a. Tensegrity I. Cell structure and hierarchical systems biology. J Cell Sci $116,1157-1173$.

Ingber, D.E., 2003b. Tensegrity II. How structural networks influence cellular information processing networks. J Cell Sci 116, 1397-1408. 
Kawkitinarong, K., Linz-McGillem, L., Birukov, K.G., Garcia, J.G., 2004. Differential regulation of human lung epithelial and endothelial barrier function by thrombin. Am J Respir Cell Mol Biol 31, 517-527.

Laurent, V.M., Cañadas, P., Fodil, R., Planus, E., Asnacios, A., Wendling, S., Isabey, D., 2002a. Tensegrity behaviour of cortical and cytosolic cytoskeletal components in twisted living adherent cells. Acta Biotheor 50, 331-356.

Laurent, V.M., Fodil, R., Canadas, P., Fereol, S., Louis, B., Planus, E., Isabey, D., 2003. Partitioning of cortical and deep cytoskeleton responses from transient magnetic bead twisting. Ann Biomed Eng 31, 1263-1278.

Laurent, V.M., Hénon, S., Planus, E., Fodil, R., Balland, M., Isabey, D., Gallet, F., $2002 b$. Assessment of mechanical properties of adherent living cells by bead micromanipulation: comparison of magnetic twisting cytometry vs optical tweezers. Journal of Biomechanical Engineering 124, 408-421.

Laurenzi, G.A., Potter, R.T., Kass, E.H., 1961. Bacteriologic flora of the lower respiratory tract. N Engl J Med 265, 1273-1278.

Lenormand, G., Bursac, P., Butler, J.P., Fredberg, J.J., 2007. Out-of-equilibrium dynamics in the cytoskeleton of the living cell. Phys Rev E Stat Nonlin Soft Matter Phys 76, 041901.

Lenormand, G., Millet, E., Fabry, B., Butler, J.P., Fredberg, J.J., 2004. Linearity and timescale invariance of the creep function in living cells. J R Soc Interface 1, 91-97.

Linder, S., Aepfelbacher, M., 2003. Podosomes: adhesion hot-spots of invasive cells. Trends Cell Biol 13, 376-385.

Maksym, G.N., Fabry, B., Butler, J.P., Navajas, D., Tschumperlin, D.J., Laporte, J.D., Fredberg, J.J., 2000. Mechanical properties of cultured human airway smooth muscle cells from 0.05 to $0.4 \mathrm{~Hz}$. Journal of Applied Physiology 89, 1619-1632.

Matthews, B.D., Overby, D.R., Mannix, R., Ingber, D.E., 2006. Cellular adaptation to mechanical stress: role of integrins, Rho, cytoskeletal tension and mechanosensitive ion channels. J Cell Sci 119, 508-518.

Mijailovich, S.M., Kojic, M., Zivkovic, M., Fabry, B., Fredberg, J.J., 2002. A finite element model of cell deformation during magnetic bead twisting. J Appl Physiol 93, 14291436.

Mizuno, D., Tardin, C., Schmidt, C.F., Mackintosh, F.C., 2007. Nonequilibrium mechanics of active cytoskeletal networks. Science 315, 370-373.

Möller, W., Kreyling, W.G., Kohlhäufl, M., Häussingger, K., Heyder, J., 2001. Macrophage functions measured by magnetic microparticles in vivo and in vitro. Journal of Magnetism and Magnetic Materials 225, 218-225.

Möller, W., Nemoto, I., Matsuzaki, T., Hofer, T., Heyder, J., 2000. Magnetic phagosome motion in J774A.1 macrophages: influence of cytoskeletal drugs. Biophys J 79, 720730.

Nicolas, A., Geiger, B., Safran, S.A., 2004. Cell mechanosensitivity controls the anisotropy of focal adhesions. Proc Natl Acad Sci U S A 101, 12520-12525.

Ohayon, J., Tracqui, P., 2005. Computation of adherent cell elasticity for critical cell-bead geometry in magnetic twisting experiments. Ann Biomed Eng 33, 131-141.

Ohayon, J., Tracqui, P., Fodil, R., Fereol, S., Laurent, V.M., Planus, E., Isabey, D., 2004. Analysis of nonlinear responses of adherent epithelial cells probed by magnetic bead twisting: A finite element model based on a homogenization approach. J Biomech Eng 126, 685-698.

Paszek, M.J., Zahir, N., Johnson, K.R., Lakins, J.N., Rozenberg, G.I., Gefen, A., ReinhartKing, C.A., Margulies, S.S., Dembo, M., Boettiger, D., Hammer, D.A., Weaver, V.M., 2005. Tensional homeostasis and the malignant phenotype. Cancer Cell 8, 241-254. 
Planus, E., Galiacy, S., Fereol, S., Fodil, R., Laurent, V.M., d'Ortho, M.P., Isabey, D., 2005. Apical rigidity of an epithelial cell monolayer evaluated by magnetic twisting cytometry: ICAM-1 versus integrin linkages to F-actin structure. Clin Hemorheol Microcirc 33, 277-291.

Planus, E., Galiacy, S., Matthay, M., Laurent, V., Gavrilovic, J., Murphy, G., Clérici, C., Isabey, D., Lafuma, C., d'Ortho, M.P., 1999. Role of collagenase in mediating in vitro alveolar epithelial wound repair. Journal Of Cell Science 112 ( Pt 2), 243-252.

Ponton, A., Warlus, S., Griesmar, P., 2002. Rheological study of the sol-gel transition in silica alkoxides. J Colloid Interface Sci 249, 209-216.

Pourati, J., Maniotis, A., Spiegel, D., Schaffer, J.L., Butler, J.P., Fredberg, J.J., Ingber, D.E., Stamenovic, D., Wang, N., 1998. Is cytoskeletal tension a major determinant of cell deformability in adherent endothelial cells? American Journal of Physiology 274, C1283-1289.

Pugin, J., Dunn, I., Jolliet, P., Tassaux, D., Magnenat, J.L., Nicod, L.P., Chevrolet, J.C., 1998. Activation of human macrophages by mechanical ventilation in vitro. Am J Physiol 275, L1040-1050.

Puig-de-Morales, M., Millet, E., Fabry, B., Navajas, D., Wang, N., Butler, J.P., Fredberg, J.J., 2004. Cytoskeletal mechanics in adherent human airway smooth muscle cells: probe specificity and scaling of protein-protein dynamics. Am J Physiol Cell Physiol 287, C643-654.

Rannels, D.E., 1996. Type II cell differentiation in culture. Am J Physiol 270, L483.

Solon, J., Levental, I., Sengupta, K., Georges, P.C., Janmey, P.A., 2007. Fibroblast adaptation and stiffness matching to soft elastic substrates. Biophys J 93, 4453-4461.

Sorokin, S.P., Brain, J.D., 1975. Pathways of clearance in mouse lungs exposed to iron oxide aerosols. Anat Rec 181, 581-625.

Stahlhofen, W., Moller, W., 1993. Behaviour of magnetic micro-particles in the human lung. Radiat Environ Biophys 32, 221-238.

Stamenovic, D., Rosenblatt, N., Montoya-Zavala, M., Matthews, B.D., Hu, S., Suki, B., Wang, N., Ingber, D.E., 2007. Rheological behavior of living cells is timescaledependent. Biophys J 93, L39-41.

Stokinger, H.E., 1984. A review of world literature finds iron oxides noncarcinogenic. Am Ind Hyg Assoc J 45, 127-133.

Stroetz, R.W., Vlahakis, N.E., Walters, B.J., Schroeder, M.A., Hubmayr, R.D., 2001. Validation of a new live cell strain system: characterization of plasma membrane stress failure. J Appl Physiol 90, 2361-2370.

Suki, B., Ito, S., Stamenovic, D., Lutchen, K.R., Ingenito, E.P., 2005. Biomechanics of the lung parenchyma: critical roles of collagen and mechanical forces. J Appl Physiol 98, 1892-1899.

Takabayshi, K., Corr, M., Hayashi, T., Redecke, V., Beck, L., Guiney, D., Sheppard, D., Raz, E., 2006. Induction of a homeostatic circuit in lung tissue by microbial compounds. Immunity 24, 475-487.

Trepat, X., Deng, L., An, S.S., Navajas, D., Tschumperlin, D.J., Gerthoffer, W.T., Butler, J.P., Fredberg, J.J., 2007. Universal physical responses to stretch in the living cell. Nature 447, 592-595.

Trepat, X., Grabulosa, M., Buscemi, L., Rico, F., Farre, R., Navajas, D., 2005. Thrombin and histamine induce stiffening of alveolar epithelial cells. J Appl Physiol 98, 1567-1574.

Trepat, X., Grabulosa, M., Puig, F., Maksym, G.N., Navajas, D., Farre, R., 2004. Viscoelasticity of human alveolar epithelial cells subjected to stretch. Am J Physiol Lung Cell Mol Physiol 287, L1025-1034. 
Trepat, X., Puig, F., Gavara, N., Fredberg, J.J., Farre, R., Navajas, D., 2006. Effect of stretch on the structural integrity and micromechanics of human alveolar epithelial cell monolayers exposed to thrombin. Am J Physiol Lung Cell Mol Physiol,

Vlahakis, N.E., Hubmayr, R.D., 2000. Invited review: plasma membrane stress failure in alveolar epithelial cells. J Appl Physiol 89, 2490-2496; discussion 2497.

Vlahakis, N.E., Schroeder, M.A., Limper, A.H., Hubmayr, R.D., 1999. Stretch induces cytokine release by alveolar epithelial cells in vitro. Am J Physiol 277, L167-173.

Walker, W.S., 1974. Functional heterogeneity of macrophages: subclasses of peritoneal macrophages with different antigen-binding activities and immune complex receptors. Immunology 26, 1025-1037.

Wang, N., Butler, J.P., Ingber, D.E., 1993. Mechanotransduction across the cell surface and through the cytoskeleton [see comments]. Science 260, 1124-1127.

Wang, N., Ingber, D.E., 1995. Probing transmembrane mechanical coupling and cytomechanics using magnetic twisting cytometry. Biochemistry And Cell Biology 73, 327-335.

Wang, N., Naruse, K., Stamenovic, D., Fredberg, J.J., Mijailovich, S.M., Tolic-Norrelykke, I.M., Polte, T., Mannix, R., Ingber, D.E., 2001. Mechanical behavior in living cells consistent with the tensegrity model. Proc Natl Acad Sci U S A 98, 7765-7770.

Wang, N., Suo, Z., 2005. Long-distance propagation of forces in a cell. Biochem Biophys Res Commun 328, 1133-1138.

Wang, N., Tolic-Norrelykke, I.M., Chen, J., Mijailovich, S.M., Butler, J.P., Fredberg, J.J., Stamenovic, D., 2002. Cell prestress. I. Stiffness and prestress are closely associated in adherent contractile cells. Am J Physiol Cell Physiol 282, C606-616.

Ware, L.B., Matthay, M.A., 2000. The acute respiratory distress syndrome. N Engl J Med 342, 1334-1349.

Waters, C.M., Ridge, K.M., Sunio, G., Venetsanou, K., Sznajder, J.I., 1999. Mechanical stretching of alveolar epithelial cells increases $\mathrm{Na}(+)-\mathrm{K}(+)$-ATPase activity. J Appl Physiol 87, 715-721.

Weeks, E.R., Crocker, J.C., Levitt, A.C., Schofield, A., Weitz, D.A., 2000. Three-dimensional direct imaging of structural relaxation near the colloidal glass transition. Science 287, 627-631.

Wendling, S., Oddou, C., Isabey, D., 1999. Stiffening response of a cellular tensegrity model. Journal Of Theoretical Biology 196, 309-325.

Wendling, S., Planus, E., Laurent, V., Barbe, L., Mary, A., Oddou, C., Isabey, D., 2000. Role of cellular tone and microenvironmental conditions on cytoskeleton stiffness assessed by tensegrity model. European Physical Journal Applied Physics 9, 51-62.

Zaman, M.H., Kamm, R.D., Matsudaira, P., Lauffenburger, D.A., 2005. Computational model for cell migration in three-dimensional matrices. Biophys J 89, 1389-1397. 
Legends of Figures

Figure 1: Schematic view of the lung alveolus showing type I and type II epithelial cells and alveolar macrophages. Type I epithelial cells are large squamous cells covering 93$97 \%$ of the alveolar surface and forming the epithelial pavement and composing the thin $(\sim 10$ $\mu \mathrm{m}$ thick) air-blood barrier. Type II epithelial cells are cuboidal and dispersed throughout the alveoli, situated between type I epithelial cells, and over the remaining surface area.

Figure 2 (modified from (Laurent et al., 2002b) and (Féréol et al., 2006)):

In A-C. Three typical geometric configurations for a bead bound to a cell considered to be a homogeneous elastic medium. The degree of bead immersion is measured by the halfangle $\alpha$ generating the cone limiting the contact area. (in A, $\alpha$ is small): The bead is in contact with the flat surface of a semi-infinite medium via a small circular area, (in $B, \alpha=\pi / 2$ ): Half the bead is immersed in a semi-infinite medium, (in C, $\alpha \approx \pi)$ : The bead is fully immersed in an infinite three-dimensional medium.

In D: Numerical estimate of the geometrical (or correcting) factor $\mathrm{E}_{\text {app }} / \mathrm{E}_{\text {cell }}(=\kappa$, see text) as a function of half-angle of immersion $\alpha$ (linear elasticity assumption). $\mathrm{E}_{\text {app. }}$ corresponds to $\alpha=\pi / 2$. The geometrical factor $\mathrm{E}_{\text {app }} / \mathrm{E}_{\text {cell }}(=\kappa$, in text $)$ is plotted versus halfangle of bead immersion $\alpha$ assuming a $20 \mu \mathrm{m}$ cell depth (infinite depth) for different assumptions of the numerical model: (i) symbols $\bullet$ and continuous black line correspond to regularly distributed isolated cells as in the study on AMs (Féréol et al., 2006), (ii) symbols $\times$ and grey line correspond to monolayer of confluent cells on rigid substrate as in the study on AECs (Ohayon et al., 2004). 
The approximate analytical solution of $\sin ^{3} \alpha$ (symbol $\square$ and grey bell-shaped curve) proposed by (Laurent et al. 2002b) provides satisfactory curve fitting in the low $\alpha$-range. There is a complete analytical solutions for $\alpha=\pi / 2$ (symbol $\boldsymbol{\Lambda}$ ) and $\alpha=\pi$ (symbol $\bullet$ ). Estimations of $\alpha$ from 3 D-reconstructions give $\alpha \approx 67^{\circ}$ for Alveolar Epithelial Cells (AECs), and $\alpha \approx 108^{\circ}$ for Alveolar Macrophages (AMs), resulting in a marked difference for the correcting factor $\mathrm{E}_{\text {app }} / \mathrm{E}_{\text {cell }}(=\kappa)$. Half angle of bead immersion in Smooth Muscle Cells (SMC) has been taken to be $\alpha \approx 38^{\circ}$ by Mijailovich et al. (Mijailovich et al., 2002) using images such the one shown in Fig. 3C, i.e., $\alpha$ in SMC appears much smaller than $\alpha$ in AECs and AMs, most likely due to differences in cell phenotypes.

Figure 3 (modified from (Laurent et al., 2002b; Féréol et al., 2006; Fabry et al., 2003)). Assessement of degree of bead immersion reveals cell type dependence. In A: Alveolar macrophages (AMs); $\alpha \approx 108^{\circ}$ (Féréol et al., 2006); in B: Alveolar epithelial cells (AECs); $\alpha \approx 67^{\circ}$ (Laurent et al., 2002b), in C: Human Smooth Muscle Cells (HASMC), $\alpha \leq 38^{\circ}$ (Fabry et al., 2003).

In A and B: Spatial reconstruction of F-actin structure in the bead region using confocal microscopic images obtained after staining with fluorescent phallotoxin (Fodil et al., 2003). Accurate bead positioning of the bead in the structure can be obtained after simulation of gravity effects on the bead. Contact points between the bead and the F-actin structure allowed accurate measurements of the half-angle of bead immersion (Féréol et al., 2006; Laurent et al., 2002b).

In C: Electron microscopic images allows only a qualitative a estimate of bead immersion in the HASMC cytoplasm. 
From A to $\mathrm{C}$, bead immersion angle dramatically decreases, meaning that the geometrical correcting factor may vary by two orders of magnitude (see Fig. 2).

Figure 4: Comparison between mechanical properties obtained in A549 alveolar epithelial cells (dark grey losanges) and rat alveolar macrophages (light grey squares) and for different levels of magnetic torque in the range 400-1200 $\mathrm{pN} \cdot \mu \mathrm{m}$. Magnetic twisting cytometry (MTC) was used and data were analyzed with the Voigt model including a single relaxation time (Eq. 9, see text for explanations).

From A to C: Elasticity modulus $\mathrm{E}$ in Pa, Viscosity modulus $\eta$ in Pa.s, relaxation time $\tau$ in s. Straight lines correspond to best linear fits.

Figure 5: Comparison between mechanical properties obtained in A549 alveolar epithelial cells (dark grey lozenges) and rat alveolar macrophages (light grey squares) for different levels of magnetic torque in the range 400-1200 $\mathrm{pN} \cdot \mu \mathrm{m}$. Magnetic twisting cytometry (MTC) was used and data were analyzed with the double Voigt model including two relaxation times (Eq. 10, see text for explanations). The "fast" component is represented on the left column; the slow component is represented on the right.

From A-B to E-F: Elasticity modulus $\mathrm{E}_{1}$ (in A) and $\mathrm{E}_{2}$ (in B) in Pa, Viscosity modulus $\eta_{1}$ (in C) and $\eta_{2}$ (in D) in Pa.s, relaxation times $\tau_{1}$ (in E) and $\tau_{2}$ in s (in F). Straight lines correspond to best linear fits.

Figure 6: Comparison between mechanical properties obtained in A549 alveolar epithelial cells (dark grey lozenges) and rat alveolar macrophages (light grey squares) for different levels of magnetic torque in the range 400-1200 pN. $\mu \mathrm{m}$. Magnetic twisting cytometry (MTC) was used and data were analyzed by the power law model including infinite 
number of relaxation times (Eqs. 11 and 12, see text for explanations). In A: exponent $\alpha$ of the power law, In B: $\mathrm{G}_{0} / 3$, elasticity modulus at $1 \mathrm{~Hz}$. Straight lines correspond to best linear fits.

Figure 7: The bead translation to bead rotation ratio plotted versus the half-angle of bead immersion $\alpha$.in the cytoplasm (in degrees). This ratio is calculated with the data obtained from the numerical model and the assumption of linear elasticity. This calculation is based on the paper by (Ohayon and Tracqui 2005). See text for explanations.

Figure 8: The magnetic torque (in $\mathrm{pN} \cdot \mu \mathrm{m}$ ) is plotted versus the bead rotation angle (in degrees) or its equivalent in terms of curvilinear bead displacement (in $\mathrm{nm}$ ) estimated at the surface of a $4.5 \mu \mathrm{m}$ diameter bead, for alveolar epithelial cells (AECs) and alveolar macrophages (AMs). MTC measurements correspond to a large range of cellular deformations (i.e., from $500 \mathrm{~nm}$ to $2500 \mathrm{~nm}$ ). Note that OMTC (Fabry et al., 2003) operates over a smaller range of cellular deformation, (i.e., less than $500 \mathrm{~nm}$ ). HASM were essentially tested by OMTC, i.e., in such a small range of cellular deformation. Cell breakage may occur in the highest range of cell deformations, (i.e., beyond $2500 \mathrm{~nm}$ ) (Hubmayr, 2005).

Figure 9 (modified from Cañadas et al. 2006): Normalized elasticity modulus $E^{*}$ and viscosity modulus $\eta^{*}$ of the overall viscoelastic tensegrity structure model as a function of the forced frequency $\mathrm{f}^{*}\left(=\mathrm{f} \cdot \tau_{\mathrm{c}}\right.$, i.e., $\mathrm{f}$ is normalized by the constant relaxation time of cables: $\left.\tau_{c}=\eta_{c} / E_{c}\right)$ on a double logarithmic scale. There are two 2 zones of predominant elastic ( $f^{*}<$ $0.1)$ and viscous $\left(f^{*}>10\right)$ effects, and a transitional zone $\left(0.1<\mathrm{f}^{*}<10\right)$ in which the effect of spatial redistribution of structural elements is maximal. The normalized elasticity modulus 
$\mathrm{E}^{*}(\bullet)$ increases in the transitional zone with a logarithmic slope $(+0.18)$ and the normalized viscosity modulus $\eta^{*}(\mathbf{\Delta})$ decreases with a logarithmic slope $(-0.24)$, the two slopes are obtained with a correlation coefficient $\mathrm{R}^{2}(=0.99)$.

Table 1 (modified from Cañadas et al. 2006): In the transitional zone of intermediate frequency range $\left(0.1 \leq \mathrm{f}^{*} \leq 10\right)$, where the respective weight of elastic and viscous effects rapidly changes with frequency $(\mathrm{f})$, viscoelastic $\left(\mathrm{E}^{*}, \eta^{*}\right)$ and hysteresivity $(\tilde{h})$ properties obtained in the viscoelastic tensegrity structure (VTS) exhibit different power law relationships (second column). For comparison, the experimental power laws $\left(\tilde{G}^{\prime}(f) \propto f^{\alpha}\right.$, $\left.\tilde{\mathrm{G}}^{\prime \prime}(\mathrm{f}) / 2 \pi \mathrm{f} \propto \mathrm{f}^{\beta}\right)$ and hysteresivity $\tilde{h}$ changes with $\mathrm{f}$, obtained in oscillatory cell experiments are presented in third column (Alcaraz et al., 2003; Balland et al., 2005; Fabry et al., 2003; Maksym et al., 2000; Puig-de-Morales et al., 2004). The power-laws established from the oscillatory response of the VTS model (Cañadas et al. 2006) not only support previous results obtained in transient loading in the same structure (Cañadas et al. 2002), but also fit the data obtained in living cell experiments with different micromanipulation methods. 
Rebuttal note for revised manuscript Ms Nº RESPNB883

Cell mechanics of alveolar epithelial cells (AECs) and macrophages (AMs)

We thank reviewers for their helpful comments and attempt to follow both editor and reviewers' recommendations.

First the manuscript has been improved for English language after proofreading and corrections made by a professional.

Second the length of the manuscript has been significantly reduced. The initial length of text and reference list was 46 pages. It has been reduced to 38 pages, corresponding to a reduction by at least $20 \%$. We have also removed Figs 3 and 10 in order to reduce the overall length of the manuscript. Note that removing more figures would have compromised the equilibrium between new material and overview of the topic.

For the same reasons, we were not able to strictly follow a suggestion of Reviewer \#1 which was to remove the 15 first pages. We still believe that the physiological description of the two cell types AECs and AMs is useful to understand the physiological meaning of the study on cell mechanics. We however considerably reduced chapters 1 and 2, i.e., chapter 1 (Introduction) by $30 \%$ and chapter 2 (Main biological functions of alveolar cells) by $45 \%$, thus following reviewer \#1 suggestion to a certain extent.

The number of references has been reduced from 144 down to 86 references which corresponds to a reduction by $40 \%$. It seems to us that, for such a review article, reducing more the number of references would be at the disadvantage of the relevant work published in the literature of the domain. Since the number of references is not limited, we hope that our reference list will become acceptable by the Journal.

All minor corrections of reviewers \#1 and \#2 have been taken into account: misprints, syntax, figures and legends have been modified as suggested by Reviewer \#2. 
Figure 1

Figure 1

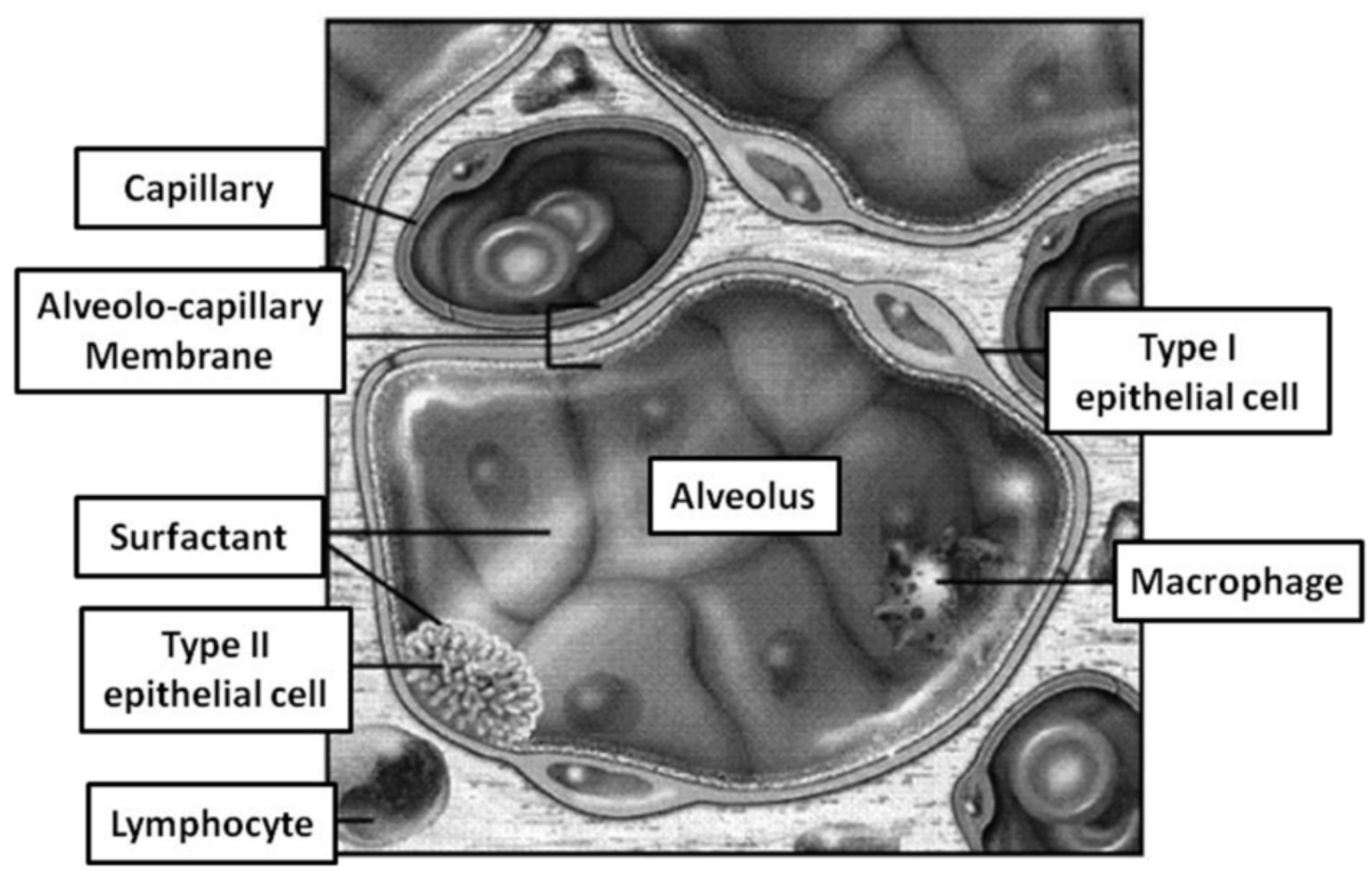


Figure 2

Figure 2

A
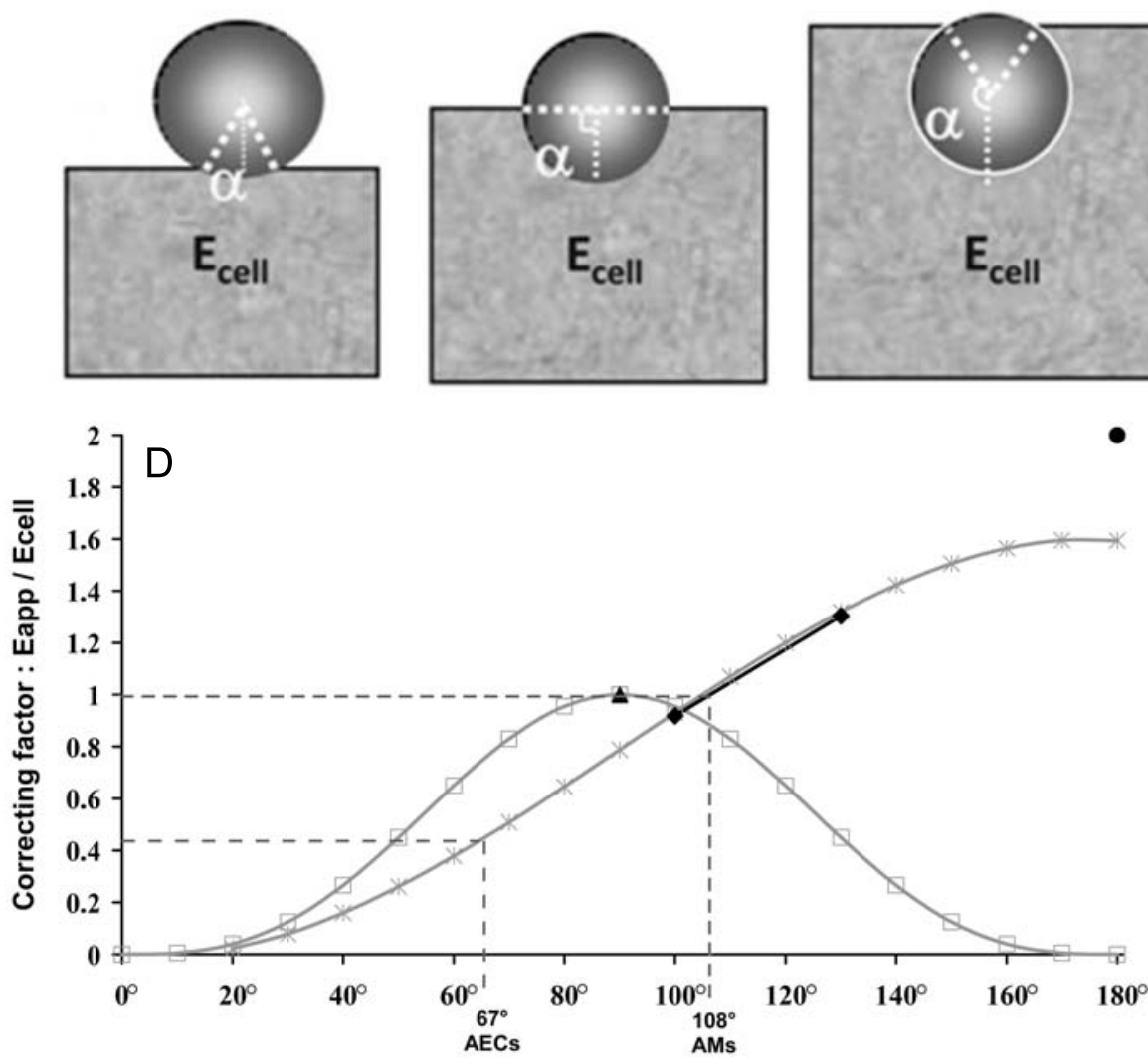

Half angle of bead immersion (degrees)
C
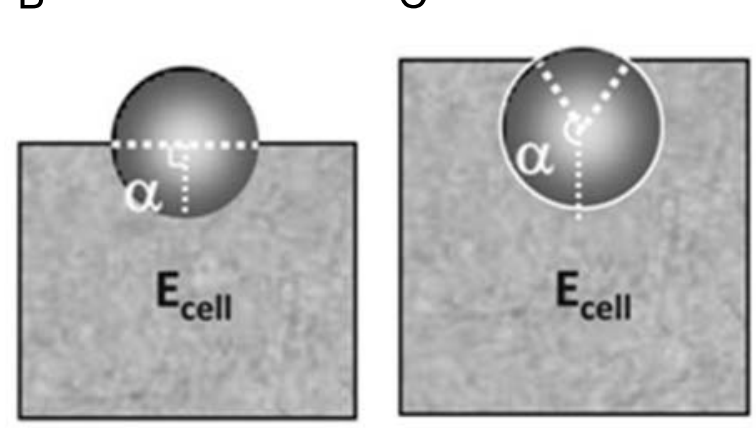
$180^{\circ}$ 
Figure 3

A
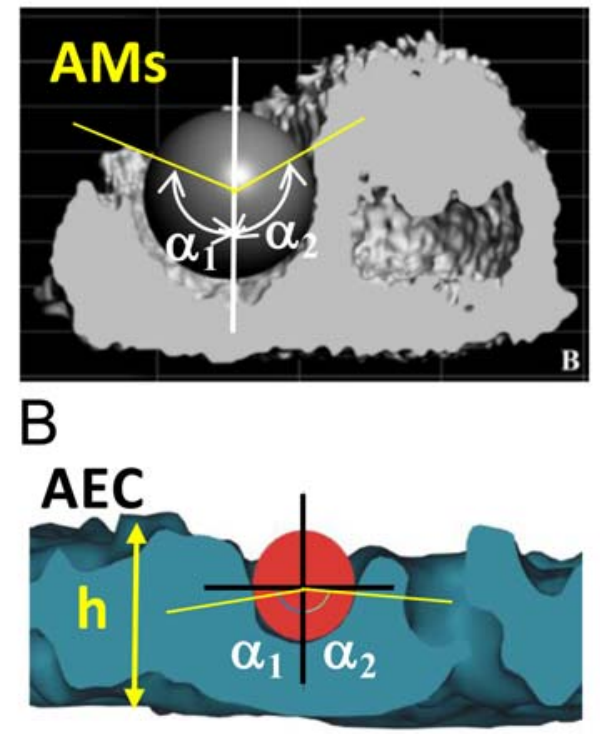

C

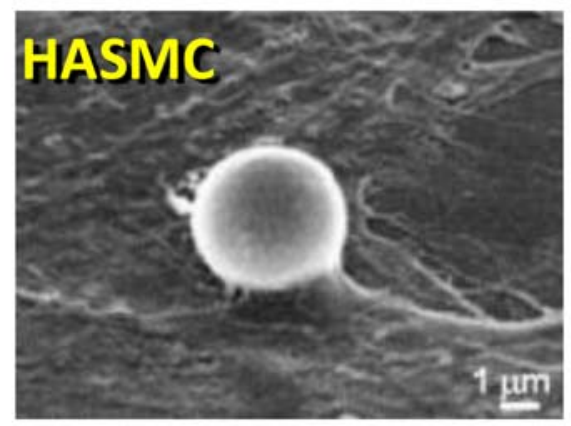

Figure 3 
Figure 4
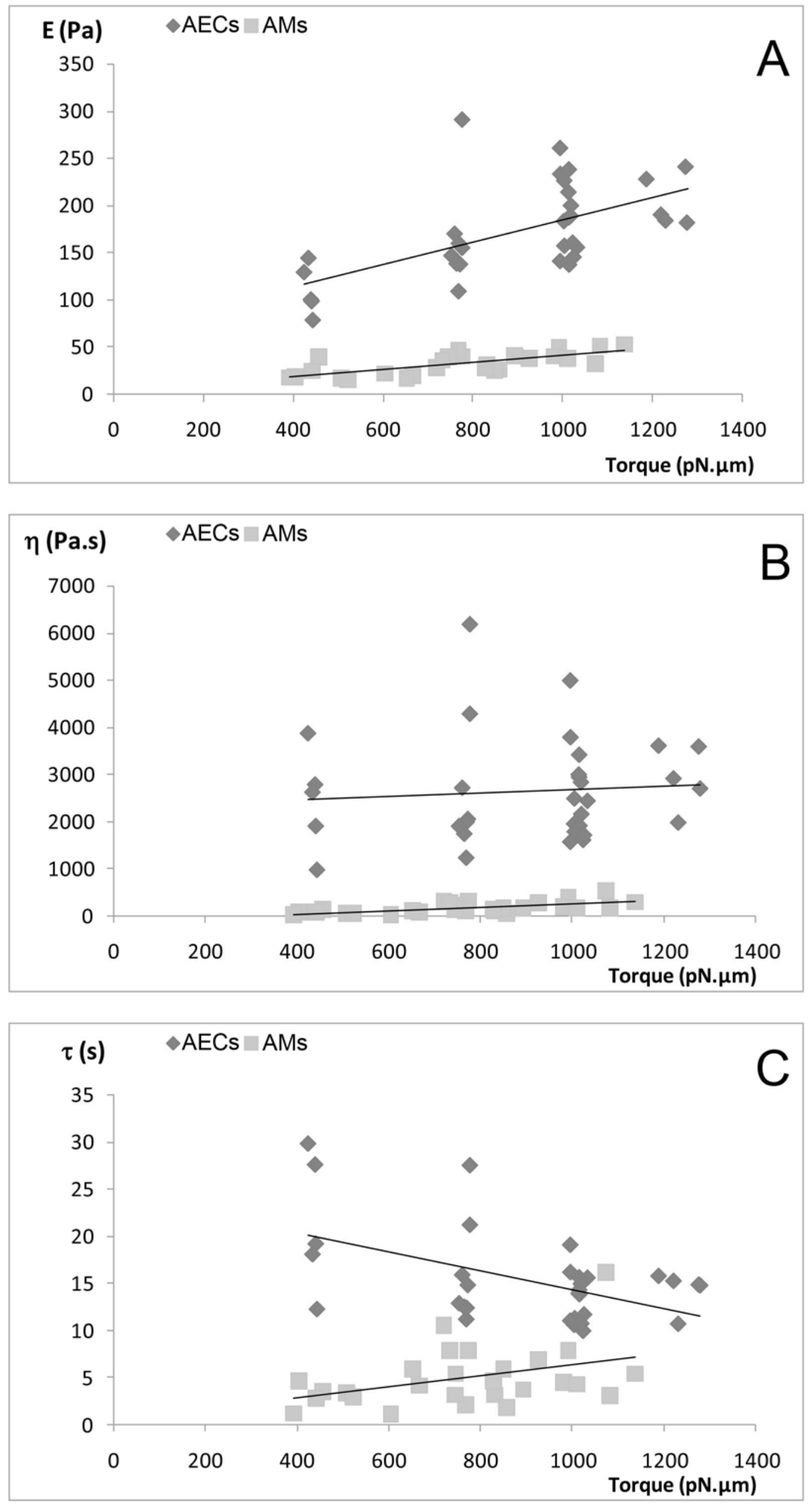
Figure 5

Figure 5
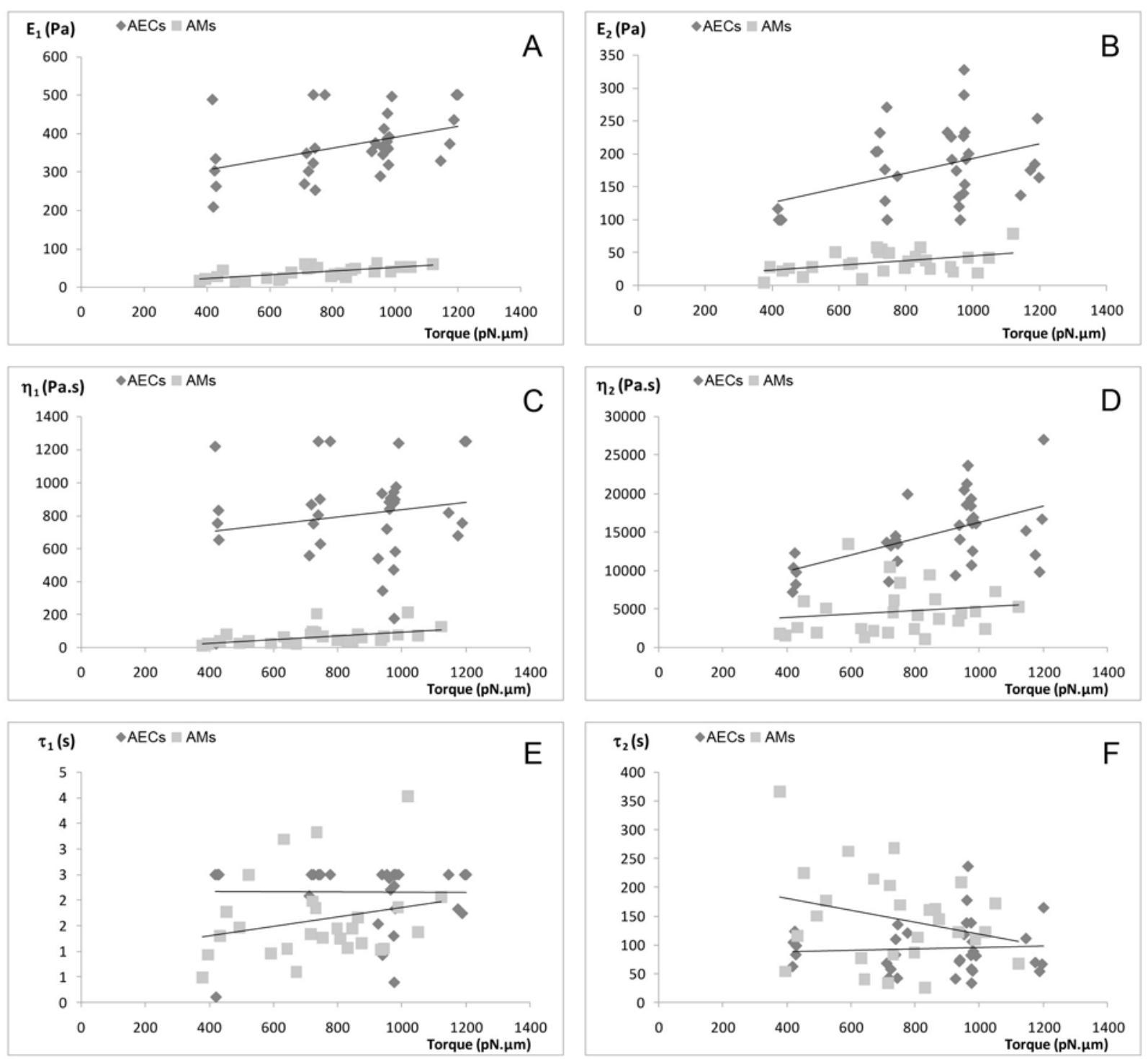
Figure 6

Figure 6
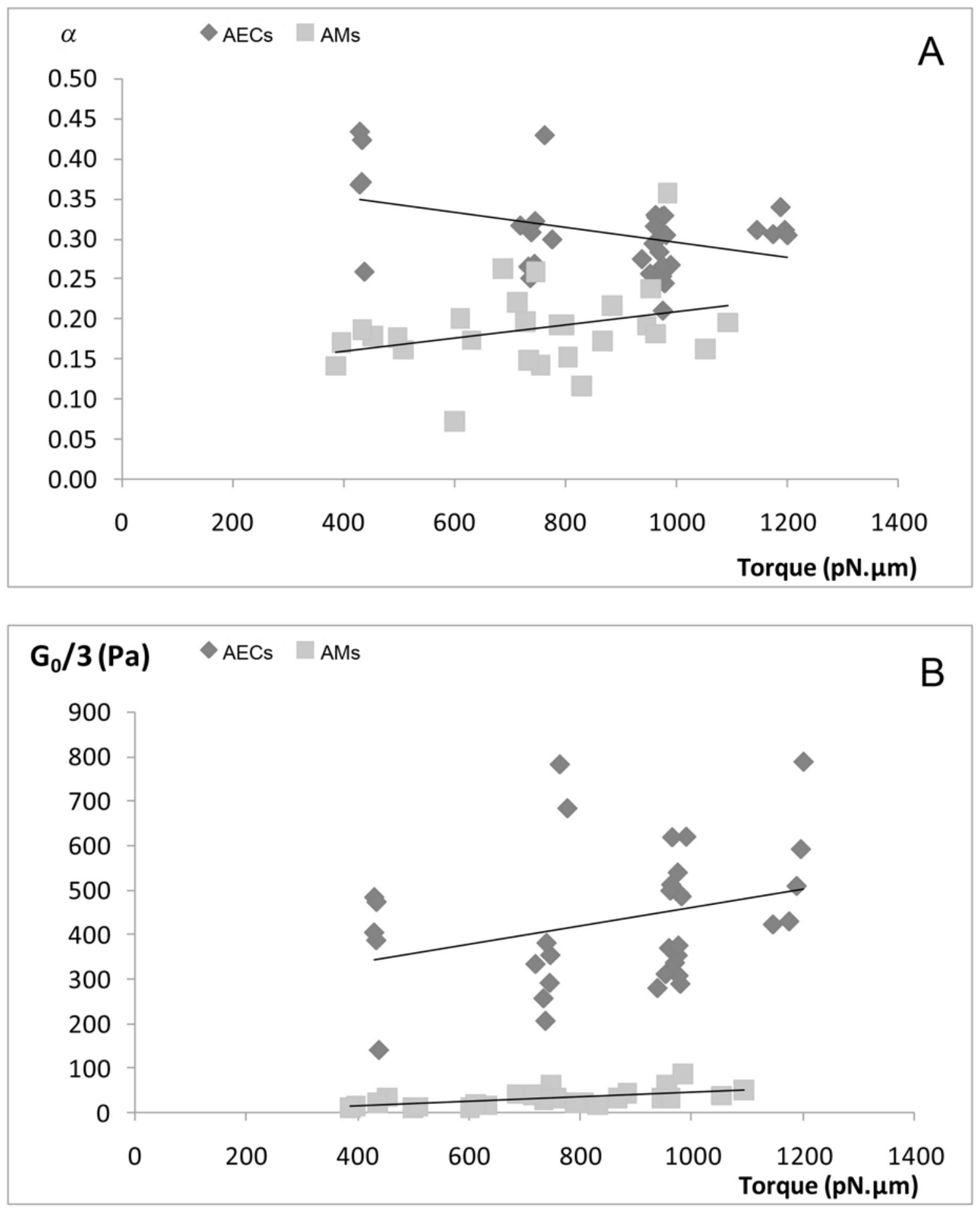
Figure 7

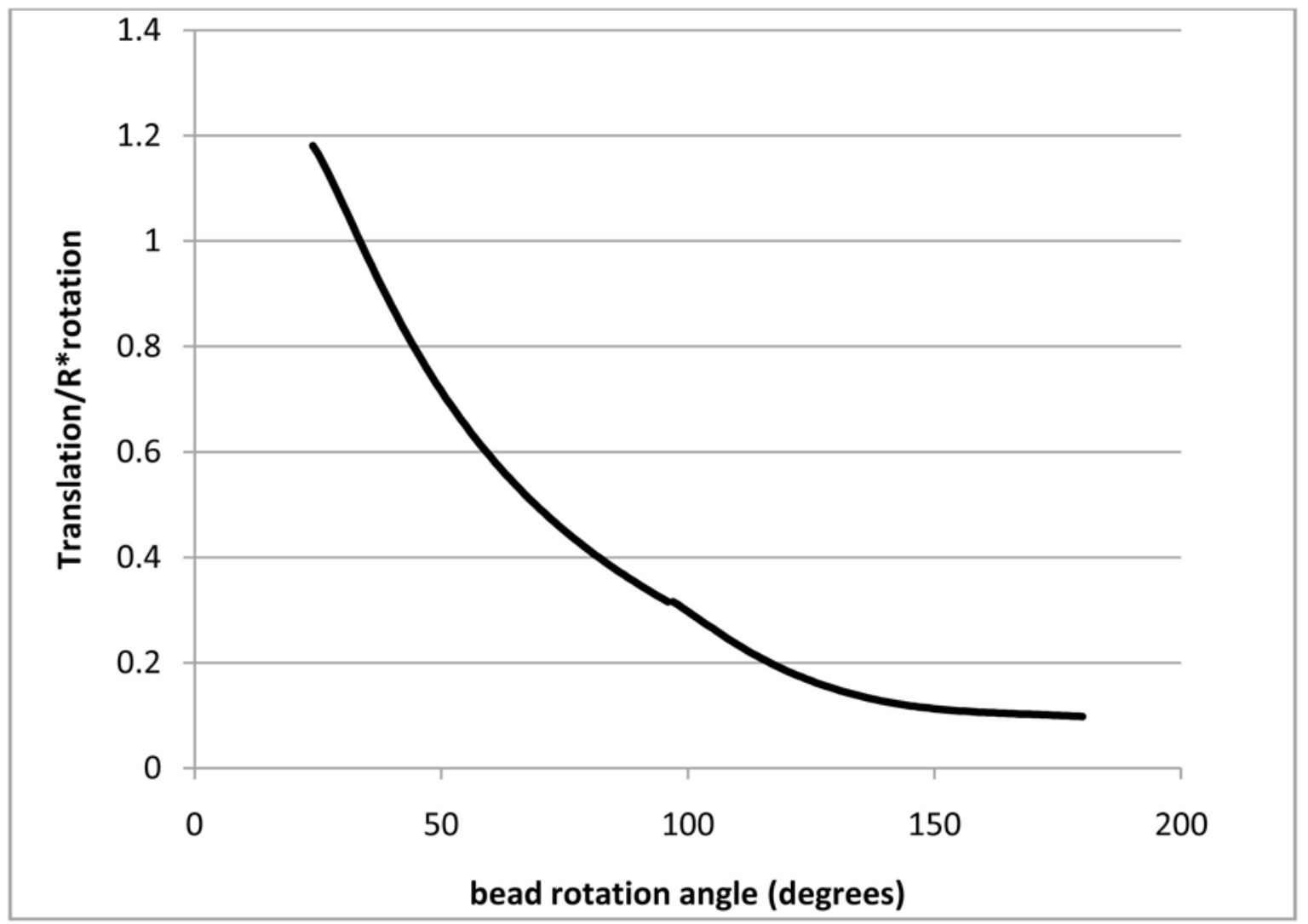


Figure 8

Figure 8

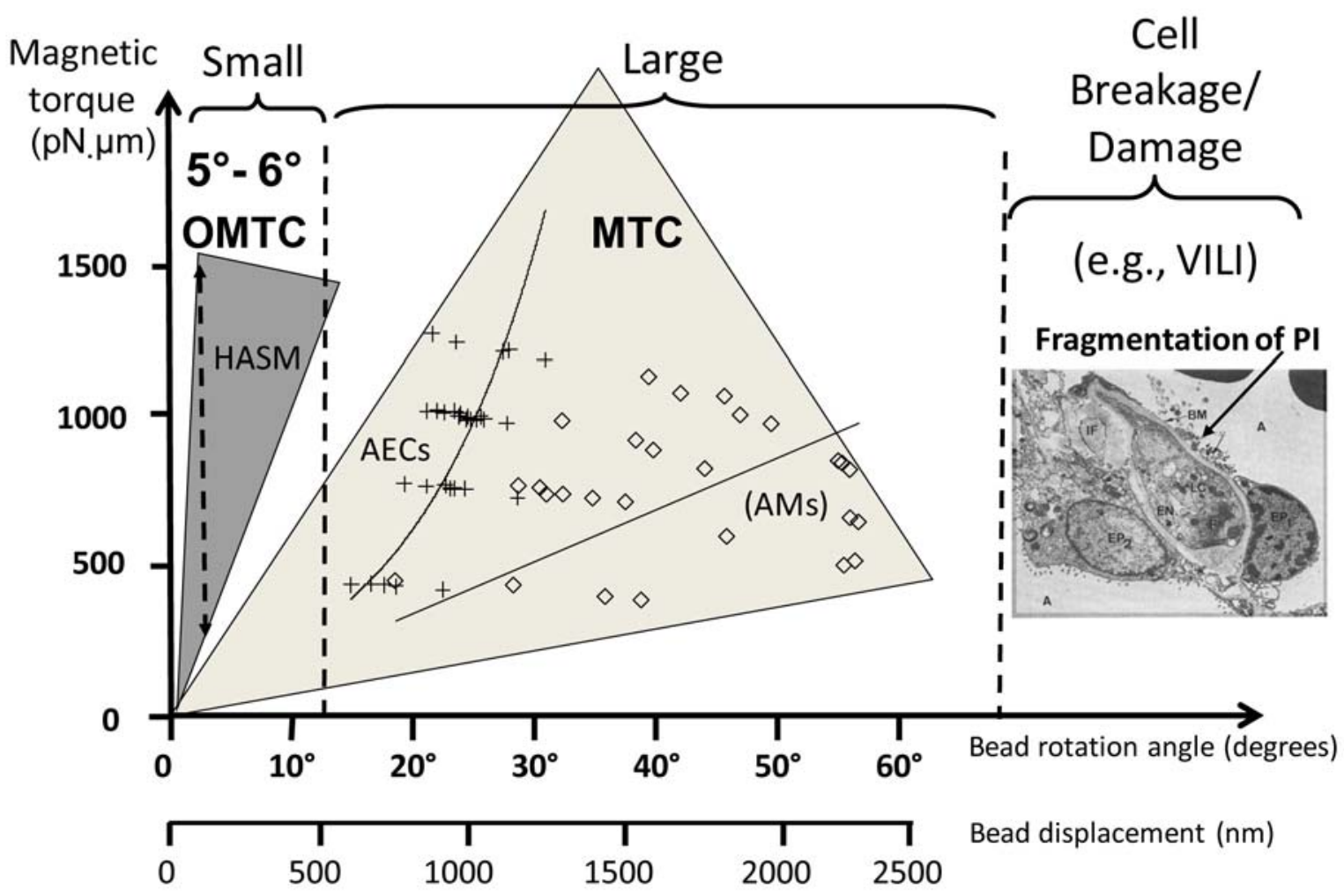


Figure 9

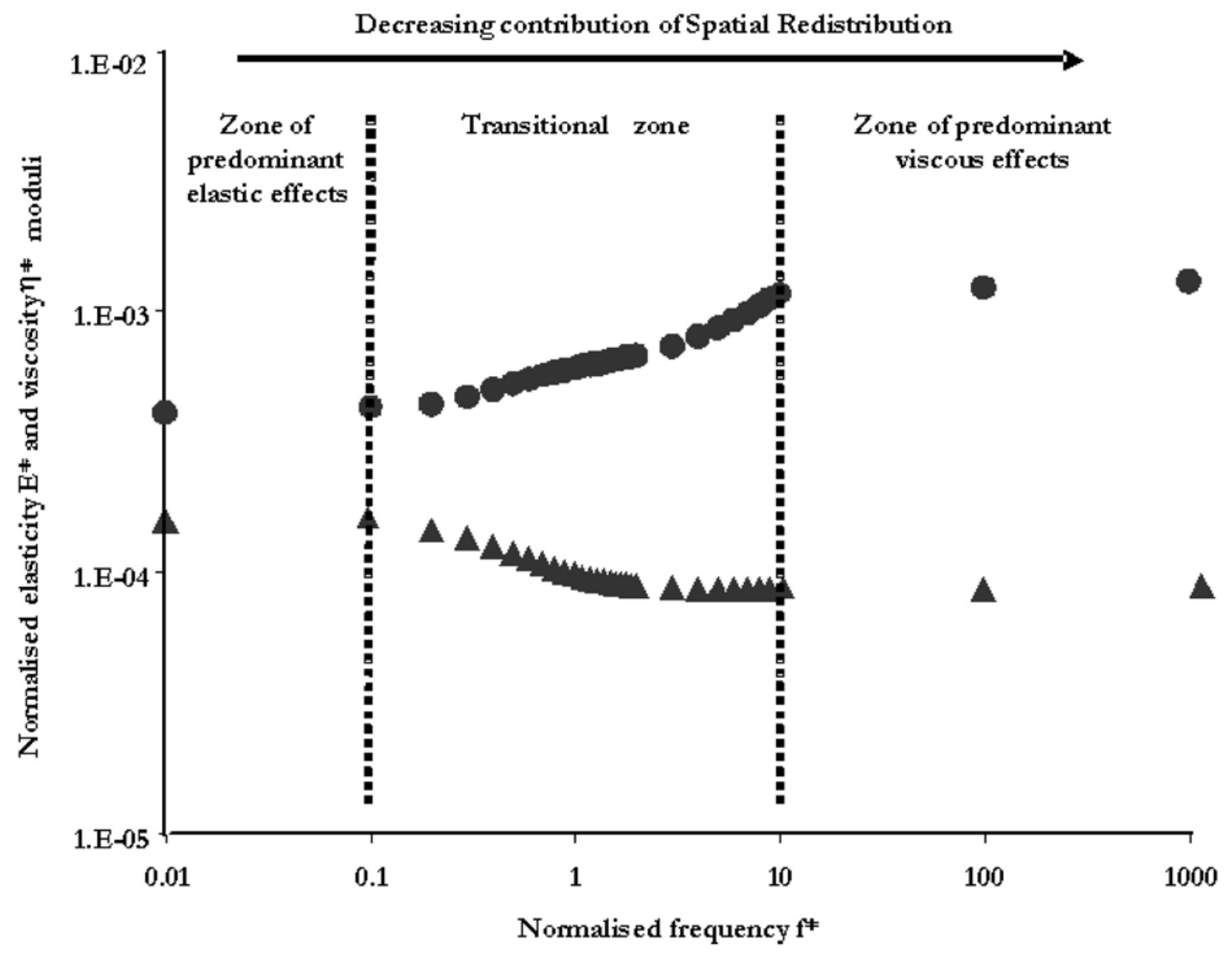


Table \#1

\begin{tabular}{|c|c|c|}
\hline & $\begin{array}{l}\text { Numerical results on the VTS } \\
\text { model }\end{array}$ & $\begin{array}{l}\text { Living cell experiments } \\
\text { (literature) }\end{array}$ \\
\hline $\begin{array}{l}\text { Elasticity } \\
\text { modulus }\end{array}$ & $\mathrm{E}^{*} \propto \mathrm{f}^{0.18}$ & $\begin{array}{c}\tilde{\mathrm{G}}^{\prime}(\mathrm{f}) \propto \mathrm{f}^{\alpha} \\
0.15 \leq \alpha \leq 0.25\end{array}$ \\
\hline $\begin{array}{l}\text { Viscosity } \\
\text { modulus }\end{array}$ & $\eta^{*} \propto \mathrm{f}^{-0.24}$ & $\begin{array}{c}\tilde{\mathrm{G}}^{\prime \prime}(\mathrm{f}) / \omega \propto \mathrm{f}^{\beta} \\
-1<\beta<0\end{array}$ \\
\hline Hysteresivity & $\tilde{h} \propto \mathrm{f}^{0.58}$ & $\begin{array}{l}\text { Constant up to } \mathrm{f}=10 \mathrm{~Hz} \\
\text { Increase from } \mathrm{f}=10 \mathrm{~Hz}\end{array}$ \\
\hline
\end{tabular}

